\title{
Quantitative estimation of landslide risk from rapid debris slides on natural slopes in the Nilgiri hills, India
}

\author{
P. Jaiswal ${ }^{1,2}$, C. J. van Westen ${ }^{2}$, and V. Jetten ${ }^{2}$ \\ ${ }^{1}$ Geological Survey of India, Bandlaguda, Hyderabad, Andhra Pradesh, India \\ ${ }^{2}$ ITC, University of Twente, Hengelosestraat 99, 7500 AE, Enschede, The Netherlands
}

Received: 12 October 2010 - Revised: 14 February 2011 - Accepted: 13 April 2011 - Published: 21 June 2011

\begin{abstract}
A quantitative procedure for estimating landslide risk to life and property is presented and applied in a mountainous area in the Nilgiri hills of southern India. Risk is estimated for elements at risk located in both initiation zones and run-out paths of potential landslides. Loss of life is expressed as individual risk and as societal risk using F-N curves, whereas the direct loss of properties is expressed in monetary terms.
\end{abstract}

An inventory of 1084 landslides was prepared from historical records available for the period between 1987 and 2009. A substantially complete inventory was obtained for landslides on cut slopes (1042 landslides), while for natural slopes information on only 42 landslides was available. Most landslides were shallow translational debris slides and debris flowslides triggered by rainfall. On natural slopes most landslides occurred as first-time failures.

For landslide hazard assessment the following information was derived: (1) landslides on natural slopes grouped into three landslide magnitude classes, based on landslide volumes, (2) the number of future landslides on natural slopes, obtained by establishing a relationship between the number of landslides on natural slopes and cut slopes for different return periods using a Gumbel distribution model, (3) landslide susceptible zones, obtained using a logistic regression model, and (4) distribution of landslides in the susceptible zones, obtained from the model fitting performance (success rate curve). The run-out distance of landslides was assessed empirically using landslide volumes, and the vulnerability of elements at risk was subjectively assessed based on limited historic incidents.

Direct specific risk was estimated individually for tea/coffee and horticulture plantations, transport infrastructures, buildings, and people both in initiation and run-out

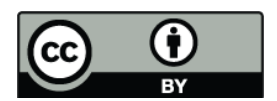

Correspondence to: P. Jaiswal

(jaiswal@itc.nl) areas. Risks were calculated by considering the minimum, average, and maximum landslide volumes in each magnitude class and the corresponding minimum, average, and maximum run-out distances and vulnerability values, thus obtaining a range of risk values per return period. The results indicate that the total annual minimum, average, and maximum losses are about US\$ 44000 , US\$ 136000 and US\$268000, respectively. The maximum risk to population varies from $2.1 \times 10^{-1}$ for one or more lives lost to $6.0 \times 10^{-2} \mathrm{yr}^{-1}$ for 100 or more lives lost. The obtained results will provide a basis for planning risk reduction strategies in the Nilgiri area.

\section{Introduction}

Landslide is one of the major natural risks in the Nilgiri hills of southern India. Landslides occur frequently on cut slopes along road and railroad (Jaiswal and Westen, 2009), and occasionally on natural slopes. In recent past, major landslide events affecting natural slopes were recorded in 1978, 1979, 1987, 1993, 1996, 2006, and 2009. These events resulted in numerous casualties and loss to properties in the Nilgiri hills (Seshagiri and Badrinarayanan, 1982; Balachandran et al., 1996). In 1993, a debris flowslide at Marapallam killed more than 50 people, and destroyed 18 houses and one mosque (Balachandran et al., 1996). In 2009, rainfall triggered more than 300 landslides in the Nilgiri area, which affected both cut and natural slopes and resulted in 80 casualties and an estimated loss of US\$ 6.5 million (Ganapathy et al., 2010).

To reduce the disastrous impact of landslides on society and to facilitate a rationale for land use planning, such as in the case of the Nilgiri hills, landslide risk quantification forms a fundamental tool in risk management process (Fell et al., 2005, 2008). Estimation of risks associated with landslides, therefore, becomes important in developing proper disaster management policies.

Published by Copernicus Publications on behalf of the European Geosciences Union. 
Although landslide risk was already defined by Varnes in 1984, the quantitative estimation of risk remains a difficult task due to problems in quantifying the individual components of the risk equation (Fell et al., 2005; van Westen et al., 2006). To quantify risk a number of different parameters are required, which are often difficult to obtain. Van Westen et al. (2006) highlighted some of the challenges in quantitative risk analysis related to the unavailability of a complete landslide inventory, the difficulty in incorporating landslide run-out for all landslide susceptible areas, and the difficulty in assessing vulnerability of elements at risk due to insufficient damage data. Even though numerous publications on the concepts of risk analysis are available (e.g., Guzzetti, 2000; Dai et al., 2002; Fell et al., 2008), these limitations make the actual quantification of spatial landslide risk rather difficult.

For a quantitative risk analysis at least three types of information are required, related to the probability of occurrence of landslides at the location of elements at risk, the quantification of the number of elements at risk exposed, and the expected degree of loss to these elements at risk given the magnitude of the landslide. The probability of occurrence of landslides forms the key component in defining different landslide hazard scenarios for risk analysis. This probability can be assessed either by computing the probability of failure of a slope (or the reactivation of existing landslides) or through the frequency analysis of past landslide events (Corominas and Moya, 2008). The latter requires making several specific assumptions on the occurrences of future events, which include the number and sizes of future landslides expected (Chung and Fabbri, 2005). If a complete landslide inventory is available then the probability of occurrence of landslides in each mapping unit can be obtained directly using the frequency of past landslides (e.g., Guzzetti et al., 2005; Jaiswal et al., 2011). However, such inventories are mostly not available and therefore a direct assessment of landslide hazard becomes difficult. Difficulties also arise if landslides are first-time failures. If the return period of triggering events for reactivated landslides is known, the estimation of the probability of future landslide activity is more straightforward (e.g., Coe et al., 2000; Catani et al., 2005).

Recently, a number of attempts have been made to quantify landslide risk (e.g., Kong, 2002; Catani et al., 2005; Zezere et al., 2007; Remondo et al., 2008). Researchers have expressed risk in different ways such as loss over a specified time period or annual loss, depending on the quality of landslide information, the scale of the study, and the aim of the analysis. However, if the analysis is meant for defining risk reduction strategies then it is recommended to express risk as annual loss in order to be able to carry out a quantitative cost-benefit analysis, and also because quantitative risk acceptance criteria for loss of life are usually expressed in per annum terms (Fell et al., 2008). In most case studies, risks are quantified for elements at risk located in the landslide initiation areas, whereas much less work has been done to assess risk by incorporating run-out distance of a landslide (e.g., Bell and Glade, 2004). If an area has a potential for hazardous debris flows then the estimation of run-out distance is essential in order to evaluate the actual risk. Several empirical methods such as the mass-change method (Cannon and Savage, 1988), the angle of reach method (Hungr et al., 2005), and process based methods (Remaitre et al., 2005) are suggested for run-out calculation. The question remains, however, how to incorporate these for the many possible landslide initiation areas in a quantitative susceptibility map with many mapping units having different spatial probabilities (van Westen et al., 2006). Process-based methods have been used to demarcate landslide hazard areas but they experience serious problems with parameterization, which makes their application problematic over larger areas, especially in a heterogeneous terrain setting (Kuriakose et al., 2009). One way to include run-out distance in risk analysis, over a large area, is to use empirical relationships such as the identification of all hazardous zones likely to affect the elements at risk that are located down slope of the landslide initiation areas, followed by a loss estimate for each element separately.

This paper deals with the quantification of direct risk to life and property (i.e., buildings, plantations, and transport infrastructures) due to first-time slope failures originating from natural slopes. The objective is to present a method that uses complete information on landslides associated with cut slopes along the road and the railroad to estimate landslide initiation hazard in data-scarce natural slopes. The obtained hazard is further used to quantify landslide initiation risk to elements at risk located on natural slopes. An empirical based landslide run-out model is used to quantify landslide run-out risk to elements located down slope of the landslide initiation areas. The output of the study will provide a basis for a cost-benefit analysis, for designing risk reduction measures based on risk acceptance criteria, and future land use planning in the Nilgiri hills of southern India.

\section{Study area}

The study was carried out in parts of the Nilgiri hills in the western Tamilnadu region of southern India (Fig. 1). It covers a $22 \mathrm{~km}^{2}$ area and contains a road and a railroad alignment that connects two cities adjacent to the study area, i.e., Mettupalayam and Coonoor. The area is famous for its tea and coffee plantations, which cover about $33 \%$ of the study area. About $59 \%$ of the area is covered by forests and $3 \%$ by horticulture plantations (spice trees and plant nursery), and the rest by settlements, bare rocks, and scrubs.

The area has three settlements, named Gandhipuran, Burliyar, and Katteri, and in the rest of the areas residential buildings are located within the tea estates. Most residential buildings have a single storey with or without column structure 


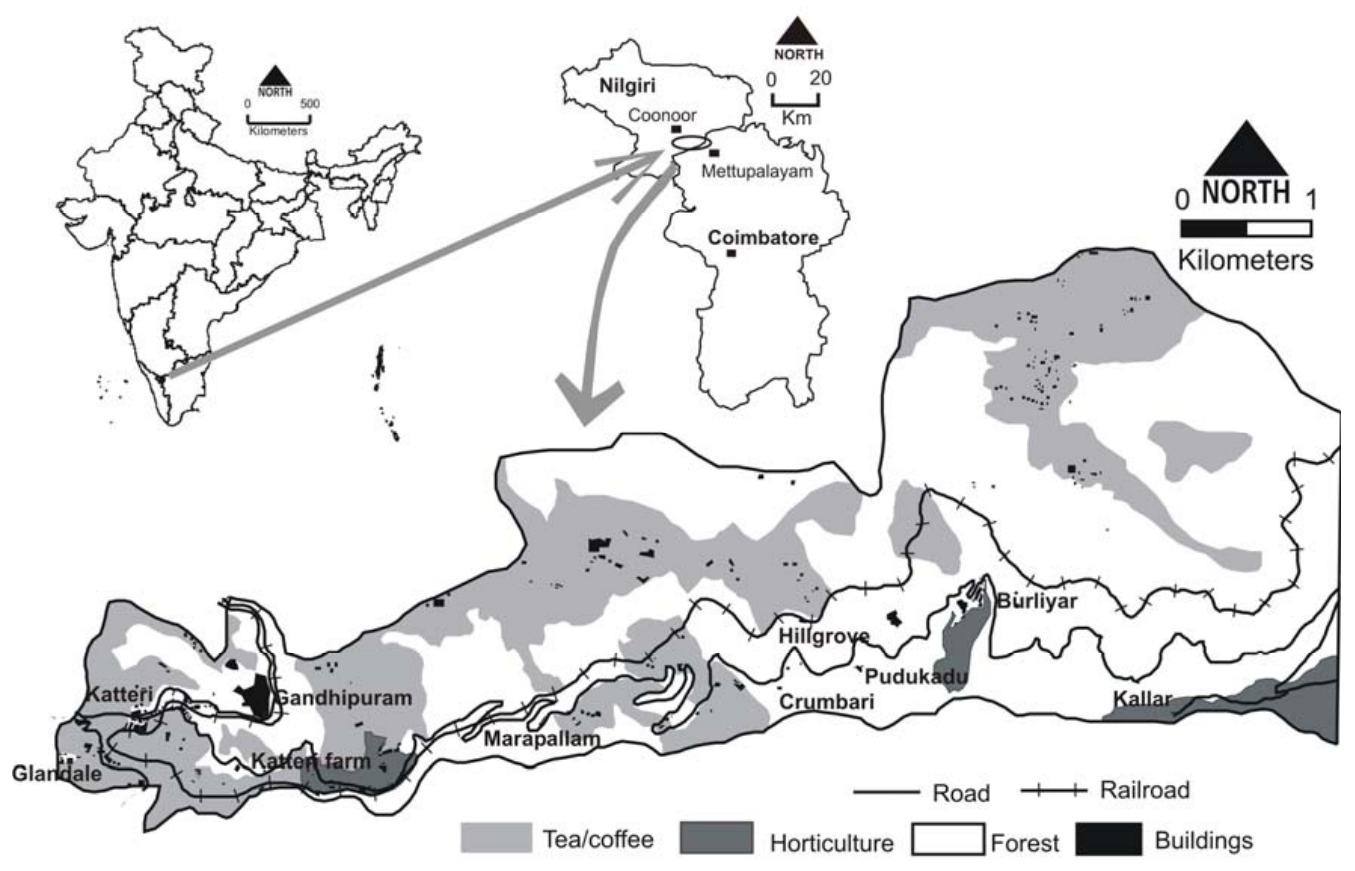

Fig. 1. Location of the study area and the elements at risk.

and are made of either tin, brick in mud, brick in cement, or reinforced concrete.

Geologically, the area exposes charnockite rocks and gneisses of Archaean age (Seshagiri and Badrinarayanan, 1982). These are overlain by soil and laterite. The area experiences rainfall during both SE monsoon (from April to July) and NE monsoon (from September to December). The intense physical and chemical weathering in sub-tropical climate have resulted in yellowish to reddish brown soils of thickness varying from less than a meter to $20 \mathrm{~m}$.

\section{Data and methods}

The approach used in this study to estimate landslide risk is presented schematically in Fig. 2. It involved the following main steps:

1. generation of a landslide inventory map showing distribution of landslides,

2. generation of a landslide susceptibility map showing areas potential for landslide initiation on natural slopes,

3. classification of the susceptibility map into three susceptible zones (i.e., high, moderate, and low) based on the percentage distribution of landslide areas and values of membership probability obtained from logistic regression analysis,

4. estimation of the number of future landslides expected and their sizes within the different susceptible zones in a given time period. This involves the analysis of the landslide inventory on cut slopes to establish a relationship between the number of landslides on cut slopes for different return periods, and those on natural slopes. The percentage distribution of cut and natural slope failures, of different size classes, and of landslide areas in different susceptible zones were then used to estimate the number of future landslides on natural slopes,

5. estimation of landslide hazard for a specific return period, calculated as the area density of future landslides of a given size in different susceptible zones,

6. estimation of run-out distances for potential landslides and associated probabilities of reaching the elements at risk,

7. mapping and quantification of the elements at risk, number of people and properties (monetary value), and assessment of their temporal and spatial probability to be in an exposed position,

8. assessment of the vulnerability of the elements at risk resulting from the specified landslide magnitudes, and

9. estimation of specific risk for each element at risk for various landslide hazard scenarios and calculation of total risk by integrating the specific losses. 
Historical landslide data
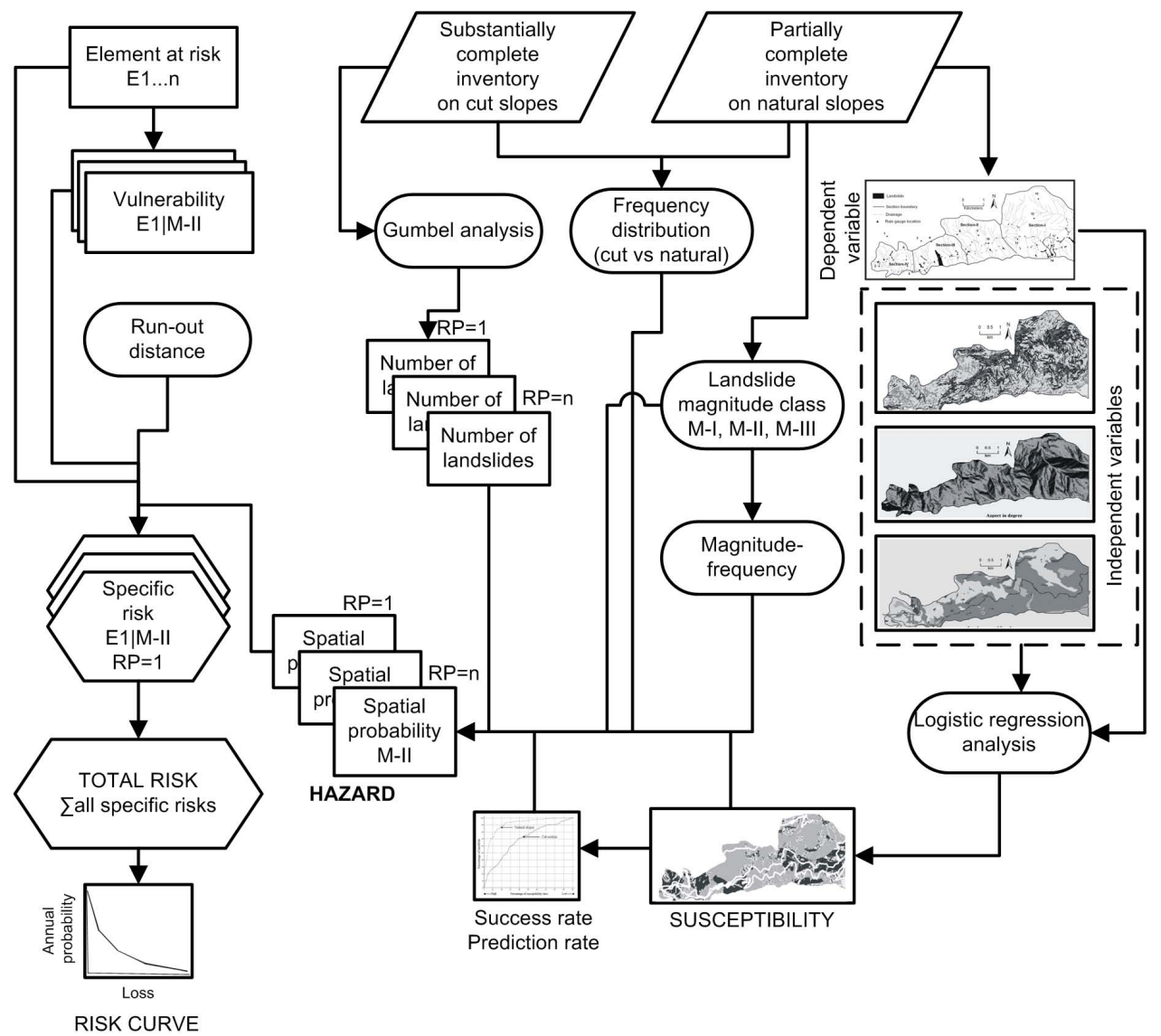

RISK CURVE

Fig. 2. Flow diagram showing the process adopted for landslide risk estimation in this study.

\subsection{Landslide inventory: survey and statistics}

A landslide inventory was prepared from historical records such as a railway maintenance register, and technical reports on landslide investigations undertaken in the study area during a $23 \mathrm{yr}$ period from 1987 to 2009 . Historical records prior to 1987 were not available for the study area. The railway maintenance records contain information on the type and amount (volume) of debris slided on the railroad. It is used for tendering contracts for debris clearance and is updated soon after each landslide triggering event. Landslides were located and mapped on a 1:10000 scale topographic map. The morphological parameters (landslide scar length, width and depth) were plotted after carefully measuring them in the field using a meter tape. The initiation (source) and run-out area were separately marked based on the field observation, image interpretation, and description given in the historical records. The availability of detailed maps and field photographs of some landslides on natural slopes facilitated in identifying the shape of landslide scars and run-out areas. Additional data such as landslide type, run-out distance, present land use, volume, probable cause, and damage details were also added to the inventory. The volume of mapped landslide scars was recalculated by multiplying the morphological parameters. The mapped landslides were digitized as polygons or points and entered in a geo-database of ArcGIS. The method and criteria used in identification and mapping of landslides are described in detail in Jaiswal et al. (2010a, 2011). The landslides were grouped into cut slope failures, occurring along the road and the railroad, and natural slope failures.

An inventory of 1084 landslides was prepared, including 1042 landslides on cut slopes and 42 landslides on natural slopes. Most landslides are shallow translational debris slides having depth less than $5 \mathrm{~m}$ and debris flowslides triggered by rainfall. Landslides initiating as slide and then converting to flow under saturated condition are grouped under "debris flowslide".

The historical records indicate that the area has experienced 120 landslide events during 1987 and 2009, where a "landslide event" is a day in which one or more landslides occurred. The number of landslides per event varies from 
1 to 166 and the number of events per year varies from 1 to 11. Particularly for landslides affecting cut slopes, the availability of a record of 120 events in a $23 \mathrm{yr}$ time (average $\sim 5.2$ events $\mathrm{yr}^{-1}$ ), including events that triggered even one landslide on a cut slope (Jaiswal and van Westen, 2009; Jaiswal et al., 2011), clearly indicates that the landslide inventory on cut slopes is substantially complete, at least for the time period 1987 to 2009 .

Out of the 120 landslide events, a total of 10 events affected natural slopes with the number of landslides per event varying from 1 to 18 . All landslides on natural slopes occurred as first-time failures with source areas ranging from 60 to $15000 \mathrm{~m}^{2}$ and volumes from 20 to $150000 \mathrm{~m}^{3}$. For some landslides information on volume was available from technical reports and for others it was estimated in the field. Major events affecting natural slopes were recorded in 1987, 2006 and 2009 when more than 100 landslides per event occurred due to very high rainfall (e.g., rainfall measuring $150 \mathrm{~mm}$ in $3 \mathrm{~h}$ on 14 November 2006 and $865 \mathrm{~mm}$ between 8 and 10 November 2009), most of which occurred on cut slopes. Other known events that triggered large landslides occurred in 1993 and 1996. In 2006, a debris flowslide (volume $\sim 16000 \mathrm{~m}^{3}$ ) east of Kallar farm had a run-out distance of $250 \mathrm{~m}$ and destroyed part of a horticulture property. In 2009, landslides destroyed five houses, two shops, two cottages of a resort, one workshop, one tourist restroom, four parked cars, two parked trucks, one swimming pool, and caused seven human casualties.

Based on technical reports and field investigation a systematic inventory of most of the landslides triggered in the 2006 and 2009 events was obtained. In 2006, 197 landslides (179 on cut slopes and 18 on natural slopes) and in 2009, 152 landslides (141 on cut slopes and 11 on natural slopes) occurred within the study area. In both the events about $28 \%$ of landslides on natural slopes were of sizes ranging between 1000 and $10000 \mathrm{~m}^{3}$. In 2006, only one landslide was more than $10000 \mathrm{~m}^{3}$ and $66 \%$ were between 100 and $1000 \mathrm{~m}^{3}$.

\subsection{Susceptibility and hazard analysis}

Landslide hazard is defined as the probability of occurrence of a potentially damaging landslide within a specified period of time and within a given area (Varnes, 1984). The hazard definition incorporates the concepts of landslide magnitude (a measure of damaging or destructive power of a landslide), geographical location (ability to identify the place where a landslide can occur), and time of failure (Guzzetti et al., 1999; Crozier and Glade, 2005). Predictions based solely on the geographical location of future landslides (susceptibility) are very common due to the fact that they are relatively easy to carry out. A variety of statistical techniques are available for such analysis, including those based on logistic regression analysis (e.g., Atkinson and Massari, 1998; Ohlmacher and Davis, 2003; Suzen and Doyuran, 2004; Nefeslioglu et al., 2008), discriminant analysis (e.g., Baeza and
Corominas, 2001; Carrara et al., 2003; Guzzetti et al., 2005), conditional analysis (e.g., Clerici et al., 2002), and weight of evidence (e.g., van Westen et al., 2003; Neuhaeuser and Terhorst, 2007). The obtained susceptibility maps generally do not provide information on the extent of landslides (accumulation area), the number of landslides, the size of landslides (small or a very large landslide), or the temporal frequency of slope failures. Therefore, in order to use such maps for risk analysis it is necessary to incorporate additional information on the number and sizes of future landslides expected within a time period (Chung and Fabbri, 2005).

For susceptibility modeling, landslides on natural slopes that occurred between 1987 and 2007 were used, and the result was validated using the landslide inventory of 2009. To obtain the spatial probability of landslide initiation, a logistic regression model was used and a pixel-based mapping unit of $10 \mathrm{~m} \times 10 \mathrm{~m}$ was selected because most landslides were small in size. Further, a pixel-based analysis facilitates faster computation of data. The source areas of the existing landslides were used as dependent variable together with 52 factor classes as independent variables, including slope angle (13 classes), aspect (12 classes), land use ( 8 classes), regolith thickness (4 classes), topographic wetness index (3 classes), internal relief, which is the height difference per unit area ( 5 classes), flow accumulation (4 classes), and distance from drainage (3 classes). From field observations it was evident that lithology (entire area is underlain by charnockite rocks) and geological structure was not a differentiating factor in landslide triggering in the area, except in the development of overburden soils, and therefore these were not included as independent variables. The method used for susceptibility analysis in the study area using slope angle, aspect, land use, and regolith thickness as independent variables is described in detail in Jaiswal et al. (2010b). Other variables, i.e., topographic wetness index, internal relief, and flow accumulation, were also derived from a digitized topographic map with $10 \mathrm{~m}$ contour spacing that was interpolated in a $10 \mathrm{~m}$ regular grid DTM. The distance from drainage map was obtained using the distance calculation function of ILWIS 3.7 wherein a continuous distance map was initially prepared for all drainages and later reclassified into different buffer zones.

The logistic regression model performed best when also topographic wetness index was excluded and the obtained coefficients were used to compute the relative spatial probability of landslide occurrence in each pixel. The model provided output values for each pixel, which range between 0 (lowest likelihood to produce a landslide) to 1 (highest likelihood). The quantitative estimate of the model performance was carried out using a success rate curve (based on landslides already used in modeling) and a prediction rate curve (based on landslides occurred in 2009) using the method proposed by Chung and Fabbri (1999).

In logistic regression, high and low values of membership probability indicate hazardous and safe mapping units, respectively. Values close to 0.5 is the most uncertain and do 
Table 1. Number of landslides expected on natural slopes in different return periods.

\begin{tabular}{lcccccc}
\hline \multirow{2}{*}{$\begin{array}{c}\text { Return } \\
\text { Period }\end{array}$} & \multicolumn{2}{c}{$\begin{array}{c}\text { Nr of landslides } \\
\text { expected on slopes }\end{array}$} & $\begin{array}{c}\text { Total } \\
\text { landslides }\end{array}$ & \multicolumn{3}{c}{$\begin{array}{c}\text { Nr of landslides on } \\
\text { natural slopes in magnitude class }\end{array}$} \\
\cline { 2 - 7 } & Cut & Natural & & M-I & M-II & M-III \\
\cline { 2 - 7 } 5 & A & B & A+B & C & D & E \\
15 & 112 & 11 & 123 & 7.26 & 3.08 & 0.66 \\
25 & 230 & 20 & 215 & 13.20 & 5.60 & 1.20 \\
50 & 279 & 28 & 253 & 15.18 & 6.44 & 1.38 \\
\end{tabular}

A is based on Gumbel analysis.

$\mathrm{B}$ is calculated as $10 \%$ of $\mathrm{A}$ and rounded.

$\mathrm{C}, \mathrm{D}$ and $\mathrm{E}$ are $66 \%, 28 \%$ and $6 \%$ of B, respectively.

not provide any information with respect to the input landslide map (Guzzetti et al., 1999). Therefore in this analysis, in order to perform hazard calculation the susceptibility map was grouped into three zones as high (spatial probability $>0.6$ ), moderate (spatial probability $0.4-0.6$ ), and low (spatial probability $\leq 0.40$ ). The high susceptible zone indicates areas having relatively high chance of producing a landslide under the given geo-environmental condition.

In order to convert the susceptibility map into a quantitative hazard map, i.e., the probability of occurrence of a landslide of a given size in a given time period, an additional information on the number and sizes of future landslides is required (Chung and Fabbri, 2005). For this the following additional information was derived and used:

1. The inventory indicates that landslides occur on natural slopes in triggering events that cause many cut slope failures (e.g., in 2006 and 2009). Based on the data of the 2006 and 2009 events, for which a complete inventory was available for both cut slopes and natural slopes, it is estimated that during such a landslide triggering event about $90 \%$ of all landslides will occur on cut slopes and $10 \%$ on natural slopes. It is assumed that the number of landslides expected to occur on natural slopes in different return periods can be obtained indirectly if a relationship between the number of landslides on cut slopes can be established for different return periods. This relationship was established using a Gumbel model and the landslide inventory on cut slopes (Jaiswal et al., 2011). Table 1 shows the number of landslides expected on cut slopes in different return periods and the derived number of landslides on natural slopes.

2. The landslides were grouped into different magnitude classes: M-I, M-II, and M-III with minimum to maximum landslide volumes ranging from 100 to $1000 \mathrm{~m}^{3}$ (average $=550 \mathrm{~m}^{3}$ ) for M-I, from 1000 to $10000 \mathrm{~m}^{3}$ (average $=5500 \mathrm{~m}^{3}$ ) for M-II, and from 10000 to $100000 \mathrm{~m}^{3}$ (average $=55000 \mathrm{~m}^{3}$ ) for M-III. Based on the available inventories the percentage distribution of natural slope failures in M-I, M-II, and M-III classes was $66 \%, 28 \%$ and $6 \%$, respectively. These values were used to estimate the relative frequency of landslide size in different return periods (Table 1).

3. For each return period, landslides were to be distributed in the three susceptible zones (high, moderate, and low) based on the result of the model fitting performance (success rate curve). Finally, hazard or the probability of occurrence of a landslide of a given size per pixel for each return period can be estimated as the ratio of the total area of landslides of a given size expected in each susceptible zone to the total area of the susceptible zone. For each magnitude class, source area of an expected landslide can be obtained by dividing the volume with the average depth of the landslide at the scarp for the given magnitude class. For the magnitude class M-I, MII, and M-III the average depth of a landslide was taken as 2, 5, and $10 \mathrm{~m}$, respectively. Thus, different hazard scenarios can be obtained considering a minimum, average, and maximum landslide size of each magnitude class.

\subsection{Assessment of landslide run-out distance}

The run-out distance of a landslide depends on several factors, including the location of the landslide source with respect to the stream below, the volume of the landslide, the type of landslide, the saturation condition of debris and rheological behaviour, and the characteristics of the path such as slope angle, roughness, terrain geometry, and land use (Dai et al., 2002). Ideally, all factors should be considered for the assessment of landslide run-out distance, but for a catchment area covering tens of square kilometers it is very difficult to obtain the required data on each of the factors.

For the analysis of run-out distances, 55 debris slides and debris flowslides that occurred between 1978 and 2004 within and adjacent to the study area were selected. The data were obtained from various reports available in the Geotechnical office at Coonoor. For the selected landslides, data 


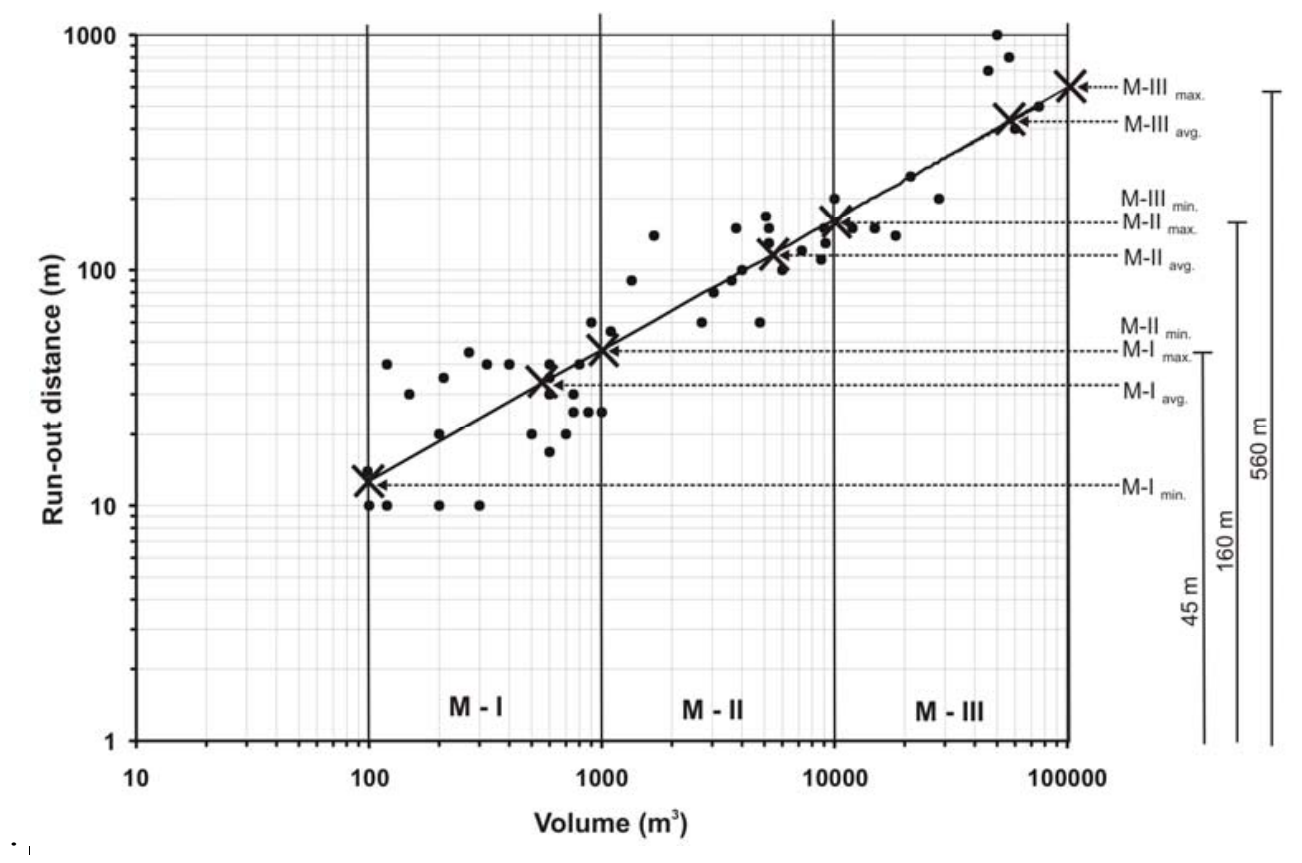

Fig. 3. Scatter plot between landslide run-out distance and volume. The black line is the fitted power trend line with scaling exponent as 0.55 . Vertical black lines indicate the magnitude classes.

on the run-out distance, landslide width and depth, and land use were available. The run-out distances varied from 10 to $1000 \mathrm{~m}$. The volume of landslides was estimated based on the description of landslide morphology (length, width, and depth) given in the reports.

In order to calculate the run-out distance for a specific landslide magnitude class for the risk analysis, an empirical relationship was established between the landslide volumes and the run-out distance in the Nilgiri area. Figure 3 shows the scatter plot taking the log of landslide volumes on the $\mathrm{x}$-axis and run-out distance on the $\mathrm{y}$-axis. The distribution has a positive power fit with scaling exponent as 0.55 . The relation can be expressed as:

$R_{\mathrm{d}}=1.0 \times V_{\mathrm{L}}^{0.55}\left(r^{2}=0.84, n=55\right)$

where $R_{\mathrm{d}}$ is the run-out distance, $V_{\mathrm{L}}$ is the volume, and $n$ is the total number of landslides taken in the analysis. For the risk analysis, run-out distance was estimated for the minimum, average, and maximum landslide volume of each magnitude class (Fig. 3). The maximum run-out distance for landslides of magnitude class M-I, M-II, and M-III was estimated to be 45,160 , and $560 \mathrm{~m}$, respectively, using Eq. (1).

The information obtained from Fig. 3 can be used to estimate risk considering the run-out distance of potential landslides of a given size located upslope of existing elements at risk. The method used to calculate risk by taking the run-out distance is demonstrated in Fig. 4. The figure shows the location of an element at risk (a house) relative to the run-out distances of different magnitude classes and landslide hazard zones. At first, from the position of the element at risk, runout distances of different landslide magnitudes are drawn upslope following the maximum gradient. Based on the relation shown in Fig. 3, landslides that are expected to reach the element at risk initiating from the three landslide hazard zones are selected for the risk analysis. For example, as shown in Fig. 4, from the high and moderate hazard zones only a landslide of magnitude M-III avg. and M-III max. reaches the house located down slope because the house is located within the run-out distance of the two landslides (M-III avg. and M-III max.). In contrast, landslides of magnitude class M-I and M-II reach the house only if they originate from the low hazard zone. By performing a similar analysis, risk can be estimated for any element or group of elements at risk considering the run-out of potential landslides of a given size.

The run-out model does not provide direct information on the intensity or destructive power of a landslide, however intensity can be inferred qualitatively as a function of landslide volume and landslide velocity (Cardinali et al., 2002). The steepness of the flow path can be used to infer velocity and landslides can be grouped into different intensity scale as suggested by Cardinali et al. (2002). But since nearly all landslides are translational occurring on steep slopes, the run-out will be fast, and therefore in this study run-out with different velocities were not differentiated. Also, the run-out model does not provide information on the total deposition area of a landslide and therefore it may not be applicable for assessing vulnerability and risk to areas likely to be inundated by debris. 
Table 2. Estimated vulnerability of elements at risk located in landslide initiation areas.

\begin{tabular}{llllllllllll}
\hline \multirow{2}{*}{ Element at Risk } & \multicolumn{9}{c}{ Vulnerability due to a landslide of magnitude class } \\
\cline { 2 - 11 } & \multicolumn{3}{c}{ M-I } & \multicolumn{5}{c}{ M-II } & \multicolumn{4}{c}{ M-III } \\
\cline { 2 - 11 } & $\min$ & avg & $\max$ & $\min$ & avg & $\max$ & $\min$ & avg & $\max$ \\
\hline Tea/coffee plantation & 0.5 & 1 & 1 & 1 & 1 & 1 & 1 & 1 & 1 \\
Horticulture plantation & 0.5 & 0.8 & 1 & 1 & 1 & 1 & 1 & 1 & 1 \\
Railroad & 0.5 & 0.8 & 1 & 1 & 1 & 1 & 1 & 1 & 1 \\
Road & 0.3 & 0.6 & 1 & 1 & 1 & 1 & 1 & 1 & 1 \\
\hline Building types & & & & & & & & & \\
Type-1 & 0.3 & 0.5 & 1 & 1 & 1 & 1 & 1 & 1 & 1 \\
Type-2 & 0.2 & 0.4 & 0.8 & 0.8 & 1 & 1 & 1 & 1 & 1 \\
Type-3 & 0.1 & 0.3 & 0.5 & 0.5 & 0.6 & 1 & 1 & 1 & 1 \\
Type-4 & 0 & 0.1 & 0.2 & 0.2 & 0.8 & 1 & 1 & 1 & 1 \\
\hline
\end{tabular}

In the run-out analysis, landslides with a volume less than $100 \mathrm{~m}^{3}$ were not considered because these occur mostly on cut slopes along the transportation lines and have very low run-out.

\subsection{Assessment of vulnerability of elements at risk}

The important elements at risk present in the study area include buildings and their inhabitants, tea/coffee and horticulture plantations, and transport infrastructures. The spatial distribution of buildings, plantation areas and transport infrastructures were mapped on 1:10000 scale from high resolution (2.5 m) Cartosat-1 data of April 2007, a topographic map, and field surveys. An inventory containing details of each element at risk was prepared based on consultations with both local inhabitants and institutions (private and government), including tea estates, railway, and highway offices. During the field surveys, 175 families were interviewed and questions were asked pertaining to their livelihood (business and income), physical status (i.e., health), family details (number of persons, age, sex, school or office working time), value of the property, and any information regarding previous landslide damages to their properties.

Buildings were mapped as individual units or as a cluster (in cases of small buildings) and digitized as polygons. The polygon map showing the spatial distribution of all building units (Fig. 1), including houses, offices, shops, factories, hospitals, schools, hotels, mosques and temples, was connected to an attribute table including type of building, number of floors, property value, etc. Houses, offices, and shops constitute about $90 \%$ of mapped buildings. Property values, including values of house-hold materials, for individual houses, shops, and factories were estimated in consultations with the owners of the property, and economic values of other buildings were obtained from data provided by different offices such as the railway and the revenue offices.
The tea/coffee and horticulture plantations are the main land use types, and transport infrastructures (road and railroad) are the main transportation lines used by tourists and local inhabitants for travelling in and out of Coonoor. The road is a $24 \mathrm{~km}$ long section of a national highway (NH-67) and the railroad is a $17 \mathrm{~km}$ long section of the UNESCO conferred world heritage railway route.

According to the Joint Technical Committee on Landslides and Engineered Slopes (JTC-1) guidelines (Fell et al., 2008), physical landslide vulnerability is the degree of loss to a given element or a set of elements at risk from the occurrence of a landslide of a given magnitude or intensity. It is expressed in a scale from 0 (no loss) to 1 (total loss). For properties the degree of loss can be expressed as either potential monetary loss or physical loss (structural damage), and can be assessed by comparing the value of damage with the actual value of the property (Alexander, 2005; Remondo et al., 2008). For persons, it can be estimated as the probability that a particular life will be lost (Fell et al., 2008),

Vulnerability depends on a number of factors (AGS, Australian Geomechanics Society and Sub-committee on Landslide Risk Management, 2000; Galli and Guzzetti, 2007) such as size and type of a landslide, its intensity, the way of impact, which defines the degree of damage, position of the element at risk, i.e., at the source or in the path of a landslide, resistance of the element against the impact of a landslide, and type of the property and its size. For the assessment of vulnerability all these factors should be considered, but as a practical limitation these factors are often difficult to quantify due to the scarcity of good damage records and therefore the assessment of vulnerability remains somewhat subjective (Dai et al., 2002).

Few attempts have been made to quantify vulnerability either qualitatively or quantitatively using the available historical damage information. For example, Finlay (1996) proposed vulnerability ranges for death from landslide debris. 


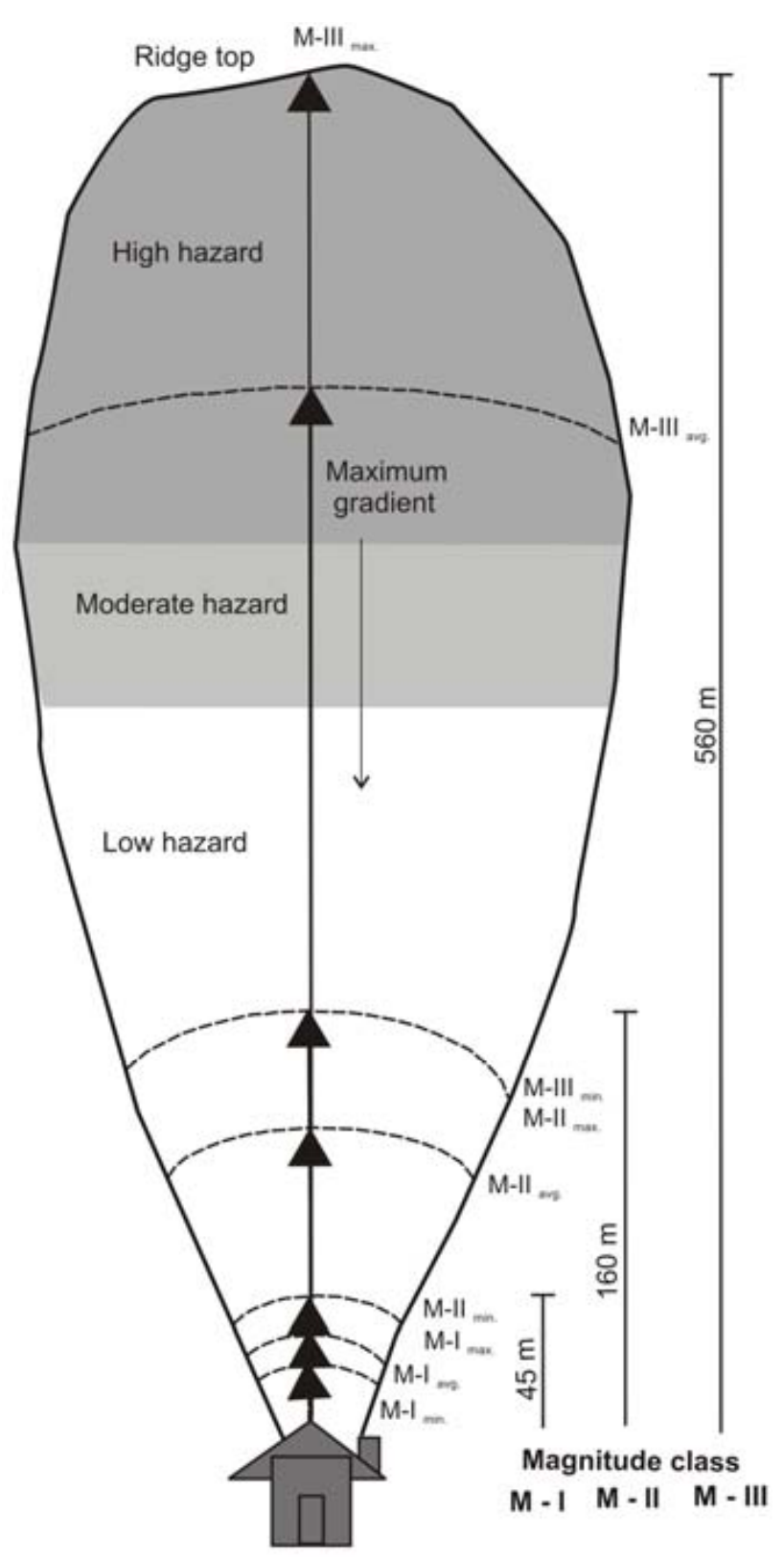

Fig. 4. Schematic diagram depicting the method used to estimate risk using the run-out distance. The figure shows the location of a house relative to the run-out distances of different magnitude classes and landslide hazard zones.

The AGS, Australian Geomechanics Society and Subcommittee on Landslide Risk Management (2000), recommended maximum vulnerability value in the event of complete collapse of a building or when the building is inundated with debris and the person is buried. However, building designs and building material have an important influence on survival rates as observed in cases of earthquakes (Coburn and Spence, 1992), and therefore building strength should also be taken into consideration in cases of landslides (Lee and Jones, 2004). Michael-Leiba et al. (2005) made a quantitative estimate of vulnerability for buildings, roads, and persons as a function of change in distance from the source of a landslide. Highest vulnerability values were assigned to elements at risk located within the path of a debris flow (i.e., elements susceptible to proximal debris flows). Galli and Guzzetti (2007) analyzed vulnerability of buildings and roads as a function of landslide area and provided minimum and maximum vulnerability curves. The values were 1 (total loss) for landslides of size ranging from $10^{3}$ to $10^{5} \mathrm{~m}^{2}$ for buildings and from $10^{2}$ to $10^{5} \mathrm{~m}^{2}$ for roads. Examples of other case studies of vulnerability factors for buildings and people calculated as a function of landslide volumes or landslide intensity are discussed in Lee and Jones (2004).

In most studies, vulnerabilities are assessed considering landslide intensity (e.g., Cardinali et al., 2002; Catani et al., 2005) and considering those landslides (e.g., debris flows) that can hit an element at risk located at some distance away from the landslide source. This is true because most often buildings are constructed on low susceptible slopes and therefore damage is more likely from landslides initiating upslope. However, certain properties such as roads, railroads, plantations, etc. are also vulnerable to landslide initiation. Therefore in this study, both the vulnerability in the initiation area of a landslide and by considering the effect of a landslide run-out were analyzed.

\subsubsection{Vulnerability of plantations}

Vulnerability of tea/coffee and horticulture plantations was estimated as the fraction of loss in the production as a consequence of a landslide of a given size. The loss was estimated per pixel area for plants located in the initiation area of a landslide. In the initiation area a small landslide (e.g., magnitude class M-I) will leave many of the plants intact (as can be seen in Fig. 5a), and therefore in per unit area (e.g., a $100 \mathrm{~m}^{2}$ area) only a certain percentage of the plants will be destroyed. If the landslide become bigger (M-II and M-III), then there will be more destruction and therefore less plants will survive.

Table 2 gives vulnerability values per pixel for different magnitude classes. The value is taken as 0.5 for a landslide of size M-I, as it will affect only $50 \%$ of a pixel area $\left(50 \mathrm{~m}^{2}\right.$ area), and the remaining unaffected $50 \%$ area will continue to yield. The vulnerability value equals 1 in cases of large landslides (M-II and M-III), which generally results in complete removal of soil cover and therefore no plant can survive. In contrast to tea, the horticulture plantations, which consist of plant nurseries and spice trees, are less vulnerable for a landslide of magnitude M-I. In such slides, spice trees are expected to withstand and losses are more from small plants and nurseries, which are difficult to extract once they are lost in landslide debris.

In this study, vulnerability of plantations affected by landslide run-out was not estimated because the method used 


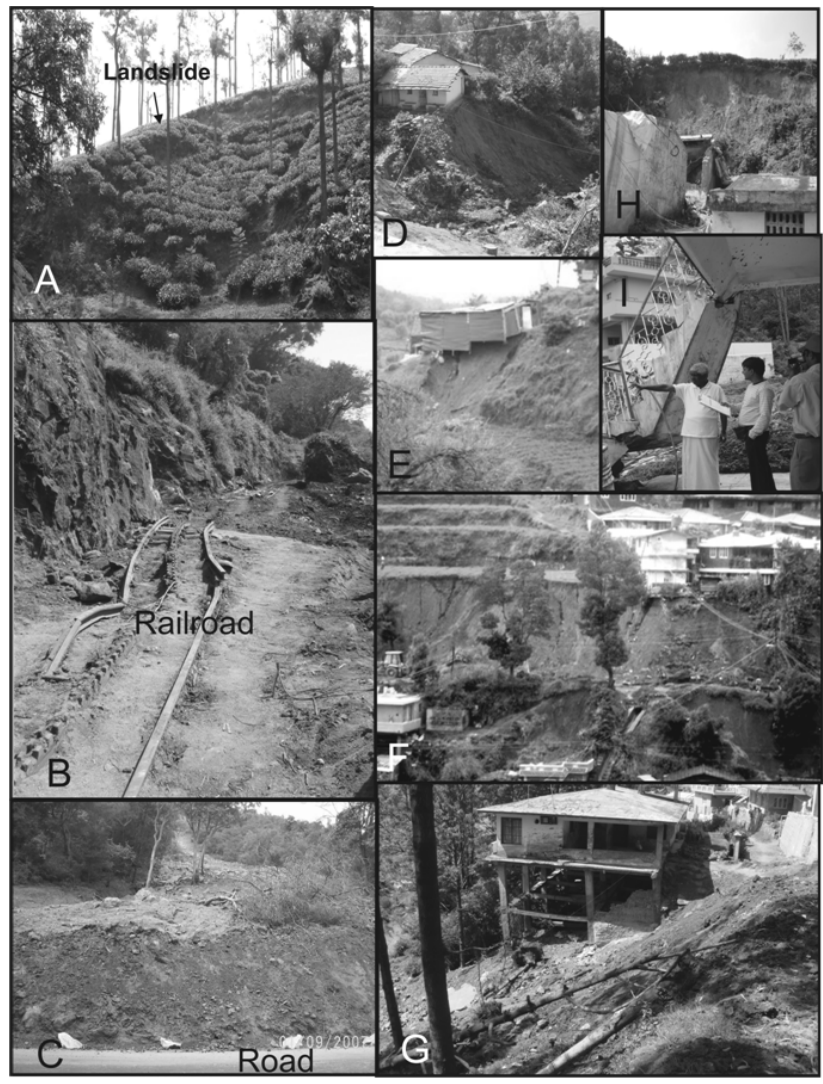

Fig. 5. Landslide damage information used for the vulnerability assessment. (A): tea plants, (B): railroad, (C): road, (D): type-2 building, (E): Type-3 building, (F) and (G): Type-4 building, (H): Type-2 building partly damaged and (I): Type-4 building partly damaged by a landslide.

does not allow the evaluation of run-out for large spatial units. Vulnerability of forest resources and indirect losses in production in years after a landslide occurrence were not estimated because these are not directly the sources of livelihood for the population.

\subsubsection{Vulnerability of transport infrastructures}

The assessment of the vulnerability of the railroad and the road was based on the information obtained from historical damaging events in the area. The vulnerability represents the ratio of the total restoration cost (US\$ pixel ${ }^{-1}$ ) to the actual construction costs (US\$ pixel ${ }^{-1}$ ). Each pixel covers a length of $10 \mathrm{~m}$.

The vulnerability values are different for infrastructures located in the initiation area of a landslide and in the run-out path. Table 2 gives vulnerability values per pixel of the road and railroad located in the initiation area of a landslide of different magnitude classes. A small landslide (M-I) generally affects only part of the slope on which the infrastructure is located. The restoration cost here includes cost of build-
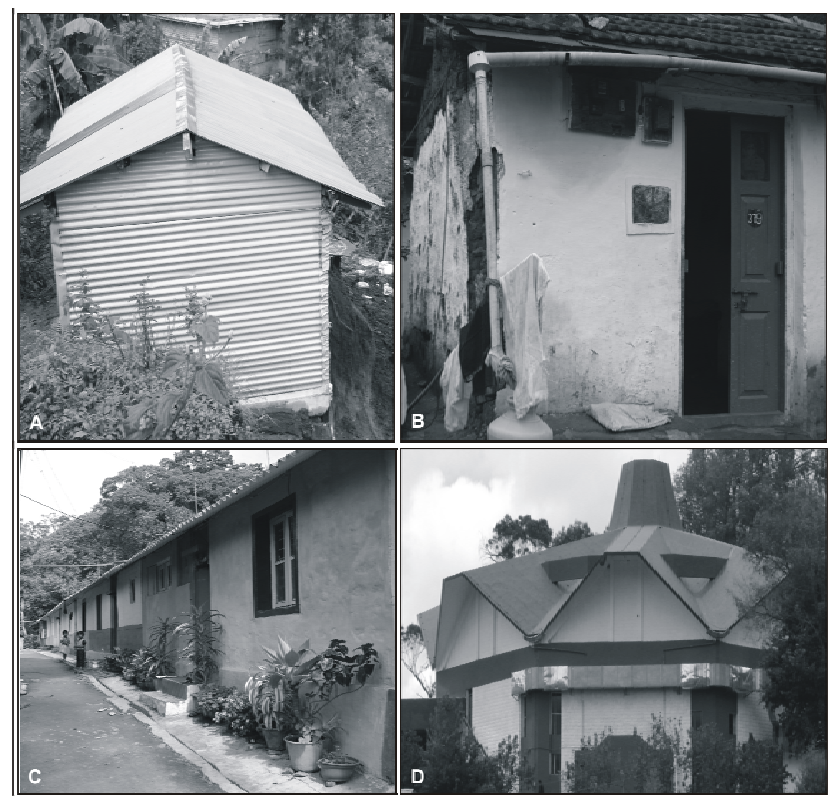

Fig. 6. Building types in the study area. (A): tin shed, (B): brick in mud without column structure, $(\mathbf{C})$ : brick in cement with column structure, and (D): reinforced concrete.

ing a retaining wall for the stabilization of the slope. The expected restoration cost for stabilizing can be $30 \%$ (vulnerability $=0.3$ ) and $50 \%$ (vulnerability $=0.5$ ) of the actual construction cost of a section of $10 \mathrm{~m}$ of a road and railroad, respectively. A slightly bigger slide can also cause some damage to the structures, and therefore in addition to the cost of constructing a retaining wall, the restoration cost will include replacing the damaged components and leveling of the ground. For a bigger landslide (M-II and M-III), the restoration cost becomes equal or exceeds the construction cost because big landslides are expected to cause complete damage of the infrastructure and therefore the vulnerability is taken as 1 (total loss). In contrast to road cases, vulnerability values are higher for railroad cases for landslides of magnitude class M-I because of the higher cost of transportation of building materials along the railroad.

Table 3 gives vulnerability values per pixel of the road and railroad located in the run-out path of a landslide for different magnitude classes. The total restoration costs here include the costs of removing landslide debris from the (rail) road and those of replacing the damaged components. The length of infrastructure being affected and the amount of debris being accumulated on the road and railroad depend on the size of a landslide. The historical records suggest that landslides of class M-I, M-II, and M-III affect about 10 to $30 \mathrm{~m}, 30$ to $50 \mathrm{~m}$, and 50 to $100 \mathrm{~m}$ length of the infrastructures, respectively and the amount of debris accumulated varies from $100 \mathrm{~m}^{3}$ to $5000 \mathrm{~m}^{3}$. For bigger landslides, not all debris is accumulated on the (rail) road, as these landslides have longer run-out and part of the debris passes the (rail) 
road. For railroad cases, the vulnerability is set to 1 for all landslide magnitude classes except for very small landslides of less than $100 \mathrm{~m}^{3}$ (Jaiswal et al., 2010a). Such landslides generally initiate from cut slopes. Figure $5 \mathrm{~b}$ shows the damage caused to the railroad by a landslide of class M-I. The landslide completely damaged a $20 \mathrm{~m}$ section of the railroad and the restoration cost was more than the actual construction cost (vulnerability $=1$ ) because it also included cost of removing landslide debris.

In road cases, the historical records indicate that landslides generally do not cause major structural damage to the road and the restoration cost mainly involves the cost of removing debris and minor repairs such as repair of parapet walls, culverts, etc., even if the landslide belongs to class M-III, as seen in Fig. $5 c$, where a landslide of $\sim 16000 \mathrm{~m}^{3}$ did not cause any structural damage to the road. However, for class M-III the total restoration cost is more than the actual construction cost, because in addition to removing debris, the cost also includes construction of a protection wall to contain further flow of debris on the road (vulnerability $=1$ ). For relatively smaller landslides (M-I and M-II), the vulnerability varies from 0.2 to 0.8 .

\subsubsection{Vulnerability of buildings}

For vulnerability calculation the buildings were grouped into four types based on the material strength of building structure: Type-1 (tin shed, Fig. 6a), Type-2 (brick in mud without column structure, Fig. 6b), Type-3 (brick in cement with column structure, Fig. 6c), and Type-4 (reinforced concrete, Fig. 6d). The Type-1, Type-2, Type-3, and Type-4 buildings respectively constitute $2 \%, 80 \%, 16 \%$ and $2 \%$ of the total buildings. The vulnerability of buildings was subjectively assessed based on limited historic incidents. The vulnerability was estimated as the ratio of monetary loss to the total value of the building and its contents. The monetary loss includes the cost of repair of damaged parts of the building and its contents, strengthening of the foundation, and the cost of removing debris from the building.

For a building located in the initiation area of a landslide, the monetary loss mostly involves cost of strengthening the foundation of the building if part of the slope underneath the building fails. In cases where the entire slope fails or the building collapses, then the building has to be reconstructed and therefore the monetary loss is equal to its value. The Type- 1 buildings are relatively more vulnerable because these are individually small, have a weak foundation, and are often located adjacent to the slope face and therefore they are subjected to total damage even if part of the slope fails. Figure 5e shows a Type-1 building whose foundation was partly removed by a small slide. Since the total value of such buildings is less, the ratio of the cost of treatment of its foundation to the value of the building is therefore always high (vulnerability $\geq 0.5$ ). The Type- 2 and Type- 3 buildings have relatively better material strength, but since the cost of slope or foundation treatment works are high, even for M-I slides the treatment cost can range from $10 \%$ to $80 \%$ of their total value. This value can increase to $100 \%$ (vulnerability $=1$ ) if the landslide is bigger than M-II or if complete reconstruction of the building is required. An example is shown in Fig. 5d and $\mathrm{f}$ where an M-I and M-II landslide requires treatment in order to protect the foundation of a Type- 2 and Type3 building, respectively. Among all building types, the Type4 buildings have the highest asset values and the strongest foundation; and since they are generally not located on steep slopes they are less likely to be affected by small slides (MI class). Even in cases of being affected by a small slope failure, the monetary loss will be much less than their actual asset value. Based on the above scenarios, different vulnerability values were assigned to the four building types located in the initiation area of a landslide of a given magnitude class (Table 2). The vulnerability value varies from 0 (M-I slide and building Type-4) to 1 (slides bigger than M-II and for all building types).

For buildings located within landslide run-out paths, vulnerability was assessed based on historic incidents. Some of the incidents included a debris flowslide of class M-III at Marapallam, which completely destroyed the entire settlement. In 2009, a debris flowslide of class M-III damaged a Type-4 building (Fig. 5g) located on its run-out path (vulnerability $=0.8$ ). In 2006, a debris flowslide of class M-II partly damaged one Type- 3 building such that the monetary loss, including removing of debris, was $70 \%$ of its value (vulnerability $=0.7$ ). In the same year a debris flowslide of class M-I completely collapsed a Type-1 building (police check post), injuring three policemen (vulnerability $=1$ ). In 2009, a landslide of class M-I damaged a Type-2 building (vulnerability $=0.8$ ) located below the slide killing five people (Fig. 5h); and in another incident a landslide of class M-II partially damaged a Type-4 building (vulnerability $=0.1$ ) located in the run-out path (Fig. 5i).

Based on the assessed values, different vulnerability values to each building type for a landslide of a given magnitude class were assigned as shown in Table 3.

\subsubsection{Population vulnerability}

Even though there have been a number of fatal landslides, the assessment of population vulnerability is prone to large uncertainty. It depends on many factors, including reflex and consciousness of the persons at the time of impact, their physical condition, age, and their perception about risk.

Some of the known incidents of landslide casualties include a landslide of class M-III in Marapallam which completely damaged all houses and killed all occupants. In 2006, a landslide of class M-I completely destroyed a Type-1 building (police check post) but these policemen escaped with major injuries (vulnerability of Type-1 building $=1$ and vulnerability of people in that building $=0.4$ ). In 2009, a slide of M-I damaged a house shown in Fig. 5h and killed five out of 
Table 3. Estimated vulnerability of elements at risk located within landslide run-out paths.

\begin{tabular}{llllllllllll}
\hline & \multicolumn{9}{c}{ Vulnerability due to a landslide of magnitude class } \\
\cline { 2 - 12 } Element at Risk & \multicolumn{3}{c}{ M-I } & \multicolumn{5}{c}{ M-II } & \multicolumn{3}{c}{ M-III } \\
\cline { 2 - 12 } & min & avg & max & min & avg & max & min & avg & $\max$ \\
\hline Railroad & 1 & 1 & 1 & 1 & 1 & 1 & 1 & 1 & 1 \\
Road & 0.2 & 0.3 & 0.4 & 0.4 & 0.6 & 0.8 & 0.8 & 1 & 1 \\
Building types & & & & & & & & & \\
Type-1 & 1 & 1 & 1 & 1 & 1 & 1 & 1 & 1 & 1 \\
Type-2 & 0.2 & 0.4 & 0.8 & 0.8 & 1 & 1 & 1 & 1 & 1 \\
Type-3 & 0.1 & 0.3 & 0.5 & 0.5 & 0.7 & 0.8 & 0.8 & 1 & 1 \\
Type-4 & 0 & 0.05 & 0.1 & 0.1 & 0.3 & 0.4 & 0.4 & 0.8 & 1 \\
\hline
\end{tabular}

Table 4. Vulnerability of people in buildings impacted by a landslide.

\begin{tabular}{lllllllllll}
\hline & \multicolumn{8}{c}{ Landslide magnitude class } \\
\cline { 2 - 11 } & \multicolumn{7}{c}{ M-I } & \multicolumn{7}{c}{ M-II } & \multicolumn{3}{c}{ M-III } \\
\cline { 2 - 11 } & min & avg & $\max$ & $\min$ & avg & $\max$ & $\min$ & avg & max \\
\hline Building types & & & & & & & & & \\
Type-1 & 0.4 & 0.8 & 1 & 1 & 1 & 1 & 1 & 1 & 1 \\
Type-2 & 0.2 & 0.6 & 0.8 & 0.8 & 1 & 1 & 1 & 1 & 1 \\
Type-3 & 0.1 & 0.4 & 0.6 & 0.6 & 0.8 & 1 & 1 & 1 & 1 \\
Type-4 & 0 & 0 & 0.2 & 0.2 & 0.6 & 0.8 & 0.8 & 1 & 1 \\
\hline
\end{tabular}

six family members (vulnerability of Type-2 building $=0.8$ and vulnerability of people in that building $=0.8$ ). In another incident in 2009 a debris flow of class M-II that damaged the house shown in Fig. $5 \mathrm{i}$ also inundated another Type-3 house located on its run-out path, killing the woman present in the house.

Based on the above incidents, vulnerability values for persons occupying different types of buildings affected by a landslide of a given magnitude class were assigned (Table 4). The vulnerability represents the probability of loosing life given the landslide impact on the building. For value 1 death is almost certain; where less than 0.5 indicates a high chance of survival. The chances of survival are relatively more if a person is occupying a Type-4 building because of the higher building strength. In this study, vulnerability to people outside of buildings was not considered.

The uncertainties in the values given in Tables 2, 3, and 4 are indicated by showing ranges of possible values (minimum, maximum and average) based on expert opinion and past events. Vulnerability for other elements at risk such as vehicles and commuters are not included in this study but were considered in another study dealing with risk of the road and railroad (Jaiswal et al., 2010a).

\subsection{Direct risk estimation}

Direct risk was estimated for elements at risk located in landslide initiation areas, and within landslide run-out zones separately.

\subsubsection{Elements at risk located in landslide initiation areas}

Direct specific risk to properties located in the initiation areas of potential landslides was estimated for a given return period using the expression adapted from Fell et al. (2005):

$\mathrm{RD}_{\mathrm{EaR}: \mathrm{Li}}=\sum_{m=1}^{m=n}\left(H_{m} \times V_{\mathrm{EaR}: \mathrm{Lm}} \times A_{\mathrm{EaR}}\right)$

where, $\mathrm{RD}_{\mathrm{EaR}: \mathrm{Li}}$ is the direct risk to the element at risk located in a landslide initiation area (US\$), $H_{m}$ is the hazard or the probability of occurrence of a landslide of size " $m$ " $(0-1), V_{\mathrm{EaR}: \mathrm{Lm}}$ is the vulnerability of the element at risk due to a landslide of size " $m$ " $(0-1)$, and $A_{\mathrm{EaR}}$ is the quantification (monetary value) of the element at risk (US\$). For each return period the specific risk was estimated considering the minimum, average, and maximum landslide volumes of each magnitude class and their corresponding minimum, average, 
and maximum vulnerability values. The specific risk for different landslide magnitudes was added for each return period to generate the combined specific risk resulting in minimum, average, and maximum landslide risk estimated for four time periods.

Risk was analyzed for tea/coffee plantations, horticulture plantations, buildings, roads, and the railroad. For each property the value for $V_{\mathrm{EaR}: \mathrm{Lm}}$ was taken from Table 2. Values for $A_{\mathrm{EaR}}$ were taken as US\$37 and US\$ 36 per pixel $\left(100 \mathrm{~m}^{2}\right)$ for tea/coffee and horticulture plantations, US\$ 1100 and US\$ 500 per pixel length $(10 \mathrm{~m})$ for railroad and road. Building costs were determined for each building separately, varying from US $\$ 300$ (Type-1 building: a police check post) to US\$ 870000 (Type-4 building: a tea factory). The elements at risk maps and the landslide susceptibility map were combined in GIS and for each pixel combined specific risk to tea/coffee plantations $\left(\mathrm{RD}_{\text {tea:Li }}\right)$, horticulture plantations $\left(R D_{\text {hort:Li }}\right)$, buildings $\left(\mathrm{RD}_{\text {bld:Li }}\right)$, road $\left(\mathrm{RD}_{\mathrm{rd}: \mathrm{Li}}\right)$, and railroad $\left(\mathrm{RD}_{\mathrm{rl}: \mathrm{Li}}\right)$ were estimated using Eq. (2). The results were presented as annualized losses and displayed as risk curves.

The above method resulted in numerous specific risk scenarios that are difficult to present in a single map for the benefit of stake holders. For each element at risk there are about 12 risk maps obtained considering four return periods and the minimum, average, and maximum landslide magnitudes. These maps provided information important for quantitative cost-benefit analysis and selecting risk tolerance criteria. But in order to facilitate land use planning, which is often carried out for a certain time period, it is important also to depict losses as expected within a given time period. Therefore, besides calculating landslide risk as annualized losses, risk was also calculated for a time period of $10 \mathrm{yr}$ using Eq. (2). Recurrence time was translated into probability by using the following equation:

$P=1-\left(1-\frac{1}{T}\right)^{N}$

where, $P$ is the probability of occurrence of the event in $N$ years and $T$ is the return period of the event.

\subsubsection{Elements at risk located within run-out of a landslide}

Direct specific risk from landslides located above the elements (properties) at risk for a given return period was estimated using the expression adapted from AGS, Australian Geomechanics Society and Sub-committee on Landslide Risk Management (2000):

$\mathrm{RD}_{\mathrm{EaR}: \mathrm{Lr}}=\sum_{m=1}^{m=n}\left(H_{m} \times P_{\mathrm{Lm}: \mathrm{EaR}} \times V_{\mathrm{EaR}: \mathrm{Lm}} \times A_{\mathrm{EaR}}\right)$

where, $\mathrm{RD}_{\mathrm{EaR}: \mathrm{Lr}}$ is the direct risk to the element at risk located within the run-out path of a landslide (US\$), $P_{\mathrm{Lm}: \mathrm{EaR}}$ is the probability of a landslide with size " $m$ ' reaching the element at risk from the upslope areas $(0-1), H_{m}$ is the hazard or the probability of occurrence of a landslide of size " $m$ " $(0$ 1) initiating in the upslope area, $V_{\mathrm{EaR}: \mathrm{Lm}}$ is the vulnerability of the element at risk due to a landslide run-out caused by a landslide of size " $m$ " $(0-1)$, and $A_{\mathrm{EaR}}$ is the quantification (monetary value) of the element at risk (US\$). $H_{m}$ and $A_{\mathrm{EaR}}$ are the components used in Sect. 3.5.1. The specific risk for different landslide magnitudes is added for each return period to generate the combined specific risk for the particular element.

Direct specific risk to persons occupying the building affected by a landslide from an upslope area was estimated using the expression adapted from AGS, Australian Geomechanics Society and Sub-committee on Landslide Risk Management (2000):

$R_{\mathrm{p}}=H_{m} \times P_{\mathrm{Lm}: \mathrm{bt}} \times P_{\mathrm{p}: \mathrm{bt}} \times V_{\mathrm{p}: \mathrm{Lmbt}}$

where, $R_{\mathrm{p}}$ is the annual probability that a person will be killed $(0-1), H_{m}$ is the annual probability of occurrence of a landslide of size " $m$ " $(0-1), P_{\mathrm{Lm}: b t}$ is the probability of a landslide with size " $m$ " reaching the building of type " $t$ " from the upslope areas $(0-1), P_{\mathrm{p}: \mathrm{bt}}$ is the probability that the person is present in the building of type " $t$ " affected by the hazard at the time of its occurrence (0-1), and $V_{\mathrm{p}: \mathrm{Lmbt}}$ is the vulnerability of the person given a landslide of size " $m$ " impacting the building of type " $t$ " $(0-1)$.

For each individual building and section of the road and railroad, the possibility of a potential landslide of a given volume (i.e., minimum, average, and maximum volumes of each magnitude class) reaching the element at risk was assessed based on the relation shown in Fig. 3 and the method described in Sect. 3.3. The various run-out distances (with their minimum, average, and maximum ranges) for the three different magnitude classes were projected upslope and checked whether, within these distances, areas were encountered with low, moderate, and high landslide initiation hazard. If the elements are located within the run-out distance, the value of $P_{\mathrm{Lm}: \mathrm{EaR}}$ and $P_{\mathrm{Lm}: b t}$ are taken as 1 ; and for landslides whose run-out do not reach the elements, the values are 0 . The values for $V_{\text {EaR:Lm }}$ for the buildings, road, and railroad are taken from Table 3 . For people occupying the buildings, $P_{\mathrm{p}: b t}$ was calculated based on the proportion of time in a year the persons occupy the building. The occupancy rate of persons depends on the use of the building. For persons occupying a house almost continuously (e.g., old persons, housewives, etc.), the value of $P_{\mathrm{p}: b t}$ was taken as 1 ; and for working people in offices and tea factories, and school children in a school, it was calculated based on $8 \mathrm{~h}$ and 5 days a week as 0.23 . For persons occupying the building during the night for $12 \mathrm{~h}$, the value of $P_{\mathrm{p}: \mathrm{bt}}$ was calculated as 0.5 . The vulnerability of persons occupying buildings of different types $\left(V_{\mathrm{p}: \text { Lmbt }}\right)$ is taken from Table 4. 
Table 5. Example of the hazard probability calculation for a 50-yr return period for landslides of a size M-I min.

\begin{tabular}{llllll}
\hline $\begin{array}{l}\text { Magnitude } \\
\text { class }\end{array}$ & $\begin{array}{l}\text { Susceptible } \\
\text { zone }\end{array}$ & $\begin{array}{l}\text { Nr of } \\
\text { pixel }\end{array}$ & $\begin{array}{l}\text { Model fitting } \\
\text { performance (success rate) }\end{array}$ & $\begin{array}{l}\text { Nr of landslides on natural slopes } \\
\text { in magnitude class M-I (see Table 1) }\end{array}$ & $\begin{array}{l}\text { Hazard probability } \\
\text { at each pixel }\end{array}$ \\
\hline & & A & B & C & D=0.5* $\times$ C $\times$ B/A \\
M-I min. & High & 54184 & 0.73 & & 0.00012 \\
& Moderate & 27170 & 0.17 & & 0.00006 \\
& Low & 137929 & 0.10 & 0.00001 \\
\hline
\end{tabular}

* landslide area ( $\mathrm{nr}$ of pixel) taken for the analysis for M-I min having volume $=100 \mathrm{~m}^{3}$.

Table 6. Landslide risk (expressed in 1000 US\$) in the study area for different return periods for both landslide initiation (I) and run-out (R).

\begin{tabular}{|c|c|c|c|c|c|c|c|c|c|c|c|c|}
\hline \multirow[t]{3}{*}{ Type of elements at risk } & \multicolumn{12}{|c|}{ Amount (US\$) in different return periods } \\
\hline & \multicolumn{3}{|c|}{$5 \mathrm{yr}$} & \multicolumn{3}{|c|}{$15 \mathrm{yr}$} & \multicolumn{3}{|c|}{$25 \mathrm{yr}$} & \multicolumn{3}{|c|}{$50 \mathrm{yr}$} \\
\hline & Min. & Avg. & Max. & Min. & Avg. & Max. & Min. & Avg. & Max. & Min. & Avg. & Max. \\
\hline Tea/coffee plantations (I) & 33 & 98 & 179 & 58 & 171 & 312 & 68 & 202 & 368 & 83 & 245 & 446 \\
\hline Horticulture plantations (I) & 6 & 17 & 33 & 11 & 30 & 58 & 13 & 36 & 68 & 15 & 43 & 82 \\
\hline Railroad (I) & 21 & 61 & 115 & 37 & 105 & 200 & 44 & 124 & 236 & 53 & 151 & 287 \\
\hline Railroad (R) & 3 & 13 & 33 & 5 & 23 & 57 & 6 & 28 & 66 & 8 & 33 & 81 \\
\hline Road (I) & 14 & 38 & 64 & 24 & 66 & 111 & 28 & 78 & 131 & 34 & 94 & 159 \\
\hline Road (R) & 1 & 2 & 16 & 1 & 5 & 29 & 2 & 6 & 34 & 2 & 7 & 41 \\
\hline Buildings (I) & 32 & 105 & 225 & 56 & 204 & 392 & 66 & 215 & 463 & 80 & 261 & 562 \\
\hline Buildings (R) & 1 & 7 & 14 & 1 & 12 & 25 & 2 & 14 & 29 & 2 & 17 & 36 \\
\hline Total (I) & 106 & 319 & 616 & 186 & 576 & 1073 & 219 & 655 & 1266 & 265 & 794 & 1536 \\
\hline Total (R) & 5 & 22 & 63 & 7 & 40 & 111 & 10 & 48 & 129 & 12 & 57 & 158 \\
\hline Total risk & 111 & 341 & 679 & 193 & 616 & 1184 & 229 & 703 & 1395 & 277 & 851 & 1694 \\
\hline
\end{tabular}

\subsection{Total risk}

The total landslide risk is obtained by integrating all specific risks. In this study, total landslide risk of properties was calculated by adding all direct combined risks to properties of a given return period, including elements located in the initiation areas and within run-out path of landslides as given in Eq. (6). The output was plotted as a series of risk curves, where the area under the curve gives the total annualized loss.

$\mathrm{RT}=\left[\mathrm{RD}_{\mathrm{EaR}: \mathrm{Li}}+\mathrm{RD}_{\mathrm{EaR}: \mathrm{Lr}}\right]$

$=\left[\begin{array}{l}\mathrm{RD}_{\text {tea: } \mathrm{Li}}+\mathrm{RD}_{\text {hort:Li }}+\mathrm{RD}_{\text {bld:Li }}+\mathrm{RD}_{\mathrm{rd}: \mathrm{Li}}+\mathrm{RD}_{\mathrm{rl}: \mathrm{Li}} \\ +\mathrm{RD}_{\text {bld:Lr }}+\mathrm{RD}_{\mathrm{rd}: \mathrm{Lr}}+\mathrm{RD}_{\mathrm{rl}: \mathrm{Lr}}\end{array}\right]$

\section{Results and validation}

\subsection{Landslide susceptibility and hazard}

Figure 7 shows high, moderate, and low susceptibility zones obtained by the logistic regression analysis. About $5.5 \mathrm{~km}^{2}$ areas are classified as high susceptible to slope failure. Most high susceptible areas are located north of Katteri, NW of Burliyar, and around drainages where torrent streams can result in debris slides.
The susceptibility map was validated using the success rate and the prediction rate curve (Fig. 8). The success rate curve shows that $73 \%$ of all landslide source areas are predicted by $25 \%$ of the classes with the highest value in the susceptibility map. Most of the landslides are in areas classified as high susceptible by the model, and only $10 \%$ of the slope failures are in areas classified as low susceptible. The corresponding model fitting performance is $73 \%$ for high, $17 \%$ for moderate and $10 \%$ for low susceptible zones. The prediction rate curve predicted about $67 \%$ of the landslides that occurred in 2009 within the high susceptible zone.

From the obtained susceptibility map and the three magnitude classes, a total of nine hazard scenarios were generated for each return period. Table 5 gives an example of the hazard probability calculated for a scenario of a 50-yr return period and M-I minimum magnitude class. For the nine scenarios, the hazard probability per pixel varies from 0.000002 to 0.0022 . The highest probability value was obtained for the high susceptible zone for scenario considering M-III max landslides and a 50-yr return period. 


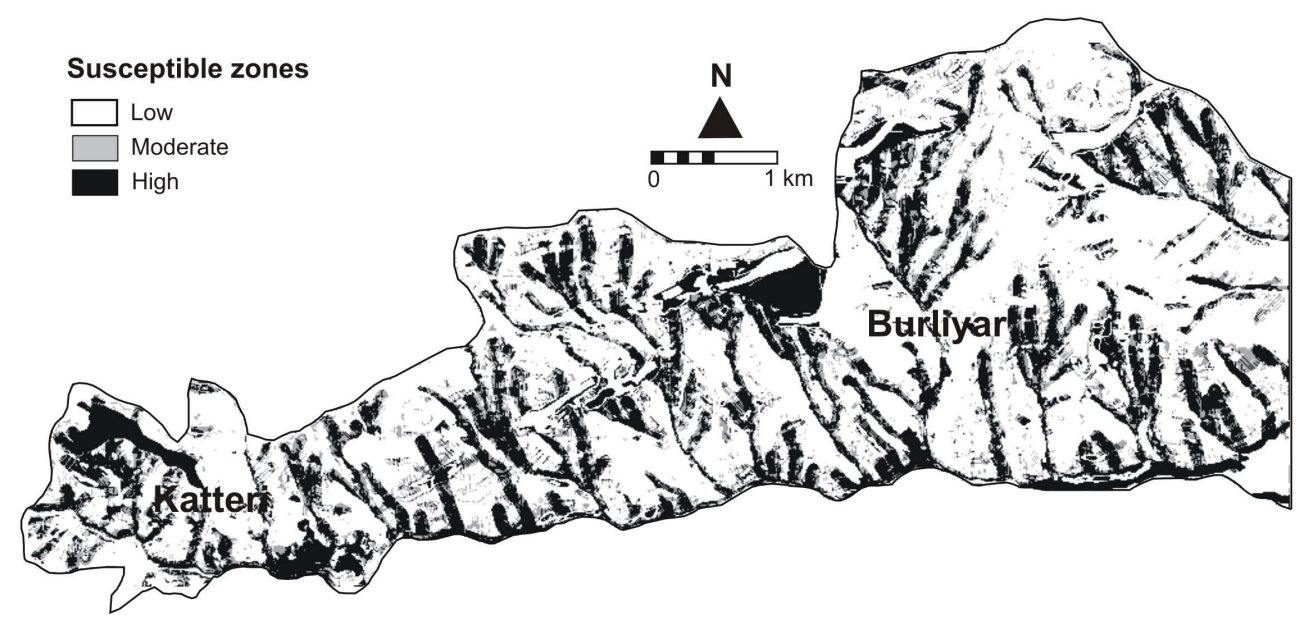

Fig. 7. Susceptibility map obtained using logistic regression analysis.

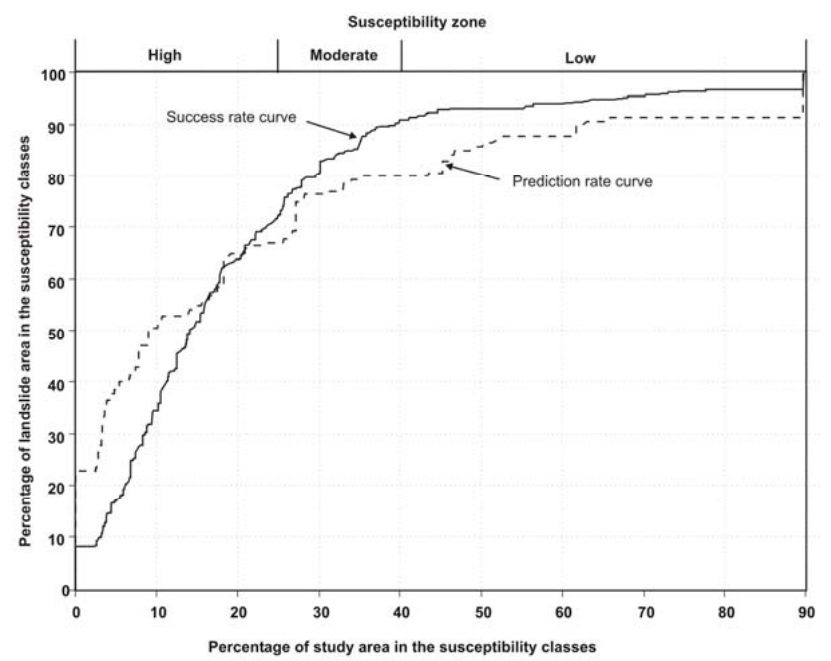

Fig. 8. Graph showing prediction rate (dashed line) and success rate (continuous thin line). The $\mathrm{x}$-axis of the graph shows the percentage of the map with highest probability values and y-axis shows the percentage of landslide area in each susceptible classes.

\subsection{Specific and total risk}

Figure 9 shows the estimated risks to different properties located in the initiation areas of potential landslides. The estimated risk is displayed as risk curves, which are plots of combined losses (US\$) versus annual probabilities of the occurrence of triggering events. Figure 10 shows the maximum risk curves for different types of buildings. The average annualized maximum loss is highest for Type- 3 buildings, because most $(30 \%)$ of these are located in high susceptible areas.

Figure 11 shows the average expected losses of all elements at risk (tea/coffee and horticulture plantations, rail- road, road, and buildings) for a time period of $10 \mathrm{yr}$. About $62 \%$ of the study area has a negligible expected loss. The expected minimum, average, and maximum losses are lower than US\$ 10 per pixel in $10 \mathrm{yr}$ for $37 \%, 28 \%$, and $23 \%$ area, respectively. High values of minimum and maximum risks, with expected economic losses greater than US\$ 50 pixel $^{-1}$ in $10 \mathrm{yr}$ occupy only $0.5 \%$ and $1 \%$ area, respectively. Such areas will deserve special attention and site specific analysis in future. Areas with expected losses between US\$ 8-50 pixel $^{-1}$ are mostly located on slopes adjacent to drainages. Such areas are vulnerable to torrent streams where debris slides can result in loss of cultivated lands and buildings located close to drainages.

For transport infrastructures, buildings, and persons occupying the buildings, risk was also estimated considering the run-out distance of potential landslides. The analysis of runout hazard showed that most of buildings are either located on ridge spurs or near to the ridge tops and therefore are not vulnerable to run-out from upslope landslides. Buildings located at Kallar farm, Burliyar, Pudukadu, Crumbari, Marapallam, Katteri, and Glandale were considered as vulnerable to landslide run-out.

Using Eq. (4), the combined specific risks to buildings $\left(\mathrm{RD}_{\text {bld:Lr }}\right)$, railroad $\left(\mathrm{RD}_{\mathrm{rl}: \mathrm{Lr}}\right)$, and road $\left(\mathrm{RD}_{\mathrm{rd}: \mathrm{Lr}}\right)$ were estimated. The specific losses for different return periods are given in Table 6. For different building types, the annual maximum expected losses were ranging between US $\$ 20$ for Type-1 buildings and US\$ 1000 for Type- 4 buildings. The combined total annual losses for properties (buildings, railroad, and road) were ranging between US\$ 2000 and US\$ 25000 .

The individual risk for persons occupying the buildings was obtained using Eq. (5). The annual probability is lowest for a person occupying a Type-4 building (tea factory) at Glandale, which is $8.0 \times 10^{-5} \mathrm{a}^{-1}$; and highest for a person occupying a Type-2 building (houses) at Pudukadu 

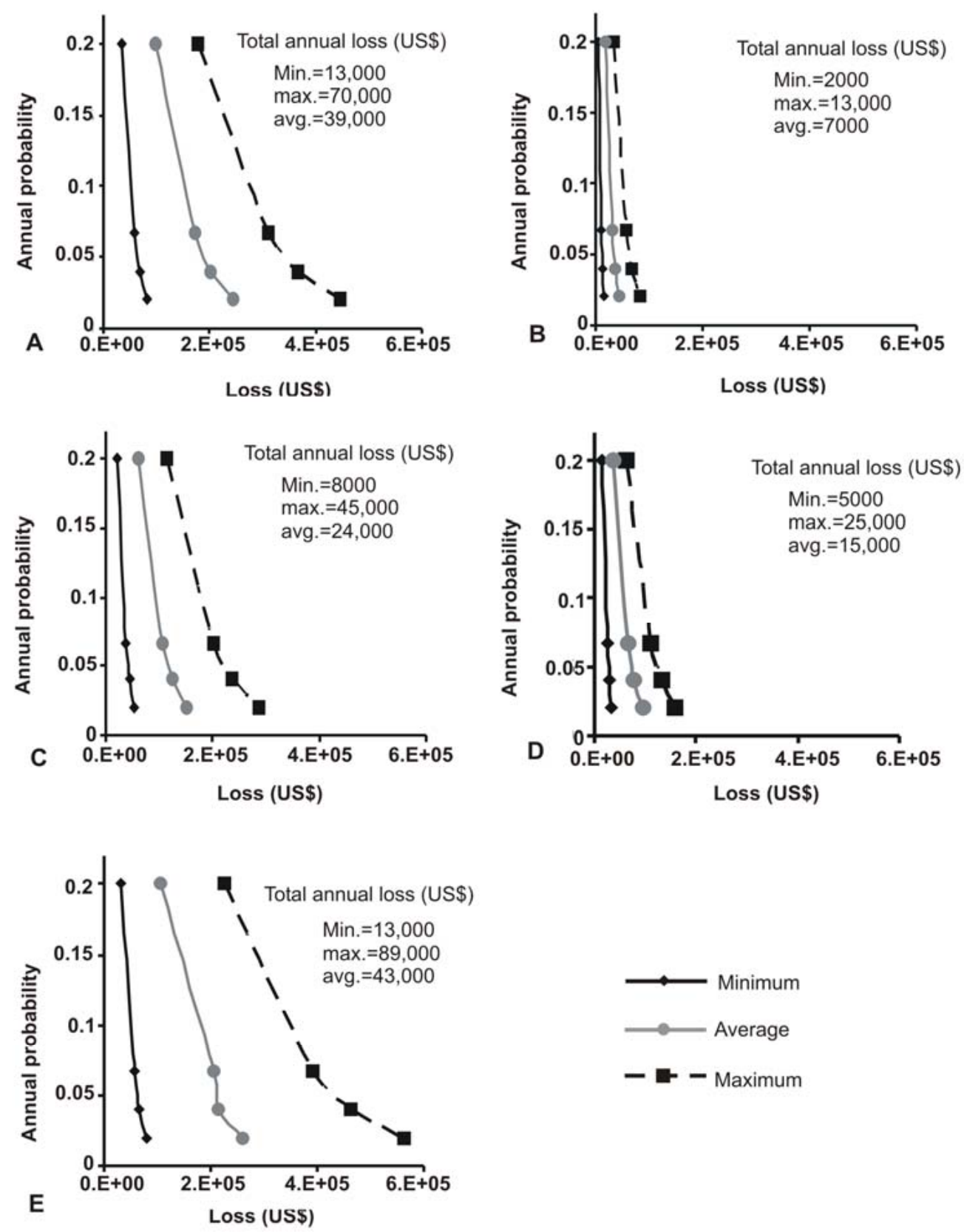

Fig. 9. Specific risk to landslide initiation displayed as risk curves. (A): Tea/coffee plantations; (B): Horticulture plantations; (C): Railroad; (D): Road; and (E): Buildings.

and a Type- 3 building (houses) at Marapallam, which is $6.1 \times 10^{-2} \mathrm{a}^{-1}$. In 1993 , about 50 people died in a landslide that occurred $500 \mathrm{~m}$ west of this house at Marapallam.

For people occupying the buildings, an estimate of the annual probability of $N$ or more lives being lost was also made and the result was plotted in a cumulative frequency - consequence plot (F-N plot). Figure 12 shows the F-N plot for the minimum and maximum values within the study area. The estimated probability of one or more lives lost varies from $2.9 \times 10^{-3}$ at Glandale to $2.1 \times 10^{-1} \mathrm{a}^{-1}$ at Katteri. For 100 or more lives lost the estimated probability varies from $2.9 \times 10^{-3}$ at Burliyar to $6.0 \times 10^{-2} \mathrm{a}^{-1}$ at Pudukadu.

The total risks for the property losses are shown in Table 6. The total minimum and maximum loss expected to properties for the study area in 5 to $50 \mathrm{yr}$ return period varies from US\$ 110000 to US\$ 277000 , and US\$ 679000 to US\$ 1694000 , respectively. 


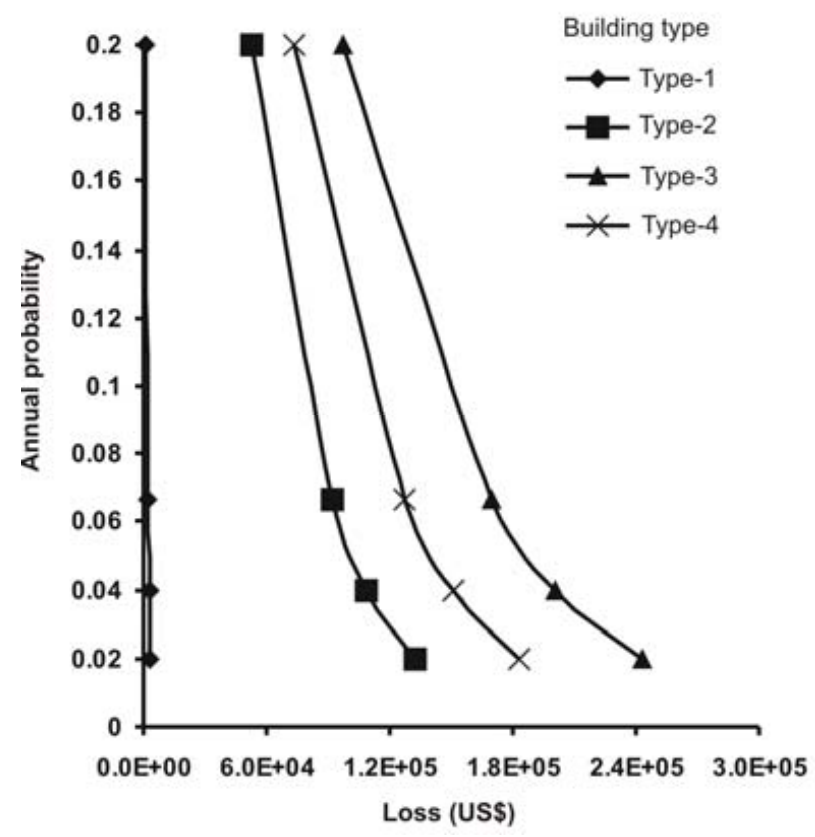

Fig. 10. Specific risk to different building types (maximum risk).

Figure 13 displays the risk curves for the total direct losses. The total annual minimum, average, and maximum losses are estimated as US\$ 44000 , US\$ 136000 , and US\$ 268000 , respectively. The figure obtained in this study can not be validated because there are no available data on landslide losses for the entire area. However, losses to buildings caused by the 2009 landslide event (see Sect. 3.1), if quantified, may be comparable to the minimum expected losses of a $25 \mathrm{yr}$ return period because landslides triggered in 2009 are individually small in size $\left(<5000 \mathrm{~m}^{3}\right)$.

\section{Discussion and conclusions}

We have presented a model to quantify risk in both initiation zones and run-out paths of potential landslides. Estimation of risk considering the run-out is important, particularly if the area has a potential for debris flowslides. Although the method has several limitations, the present method is suitable for assessing direct risk for individual elements at risk by considering the run-out distances. This method is also applicable for risk analysis in a large area where the interest is on assessing the hazard at the location of the elements at risk. Thus, if hazard mapping is carried out with the aim to analyze risk, then it is reasonable to use the proposed run-out model the way it is used here to estimate risk to the exposed elements rather then incorporating run-out distance itself in the susceptibility model.

In our earlier work we obtained a susceptibility map based on four thematic variables (Jaiswal et al., 2010b). The model predicted $35 \%$ of the landslides of 2009 events within the high susceptible zone. By adding additional thematic information on internal relief, flow accumulation, and distance from drainage, the prediction capability of the susceptibility model was increased to $63 \%$ in the high susceptible zone. Because of the better prediction skill we used the improved susceptibility map in the present work.

Run-out distances were based on a simple empirical relation with volumes based on historical events in the area without taking into account many other factors that might play a role. The estimation of run-out distances was carried out manually, starting from those elements at risk that are located down slope of areas with low, moderate, and high susceptibility for landslide initiation. This procedure could be automated using a GIS. This is one of the topics for future study.

Another issue related to the run-out model is the maximum travel distance considered in the analysis obtained based on Eq. (1) and the actual travel distance measured in the field. For example, landslide sizes with volume $1000 \mathrm{~m}^{3}$ and $10000 \mathrm{~m}^{3}$ have the maximum measured run-out distance of 60 and $200 \mathrm{~m}$, respectively, as shown in the scatter plot in Fig. 3. But in the analysis we have taken, these values as 45 and $160 \mathrm{~m}$ as estimated using Eq. (1). Since the run-out risk also depends on the maximum run-out distance, a certain degree of uncertainty is induced due to the estimated value, which is lower than those measured in the field. However, due to the large variation in the measured run-out distances, it was reasonable here to consider the best-fit value.

The ultimate aim of a quantitative risk analysis is to facilitate financial and cost-benefit analysis for planning risk reduction strategies. For this the risk should be expressed as annualized loss. For an optimal estimation of annualized loss, landslides of different sizes and their annual probability of occurrence should be analyzed. However, such an analysis requires a substantially complete landslide inventory for a long period of time, which in fact is seldom available, at least for landslides affecting natural slopes. The proposed method compensates for the gap of data scarcity and provides a possibility of estimating landslide risk on natural slopes based on more complete information of landslides in untreated excavated slopes along roads and railroads in the same area. Since roads require immediate clearance, maintenance records are expected to be more complete.

The highest loss was estimated for buildings, followed by tea/coffee plantations, railroad, road and lowest for the horticulture plantations. The level of expected annual losses of buildings and tea/coffee plantations is comparable, as plantations have a larger spatial coverage and $92 \%$ of the buildings were located in low susceptible zones. It should be noted that the expected losses for plantations could be much higher if we estimate the risk of landslide run-out for this.

Although we initially expected that run-out losses would be greater than initiation losses, the results show that the total annual average run-out loss is only $10 \%$ of the total annual average initiation losses. This is because for run-out losses 

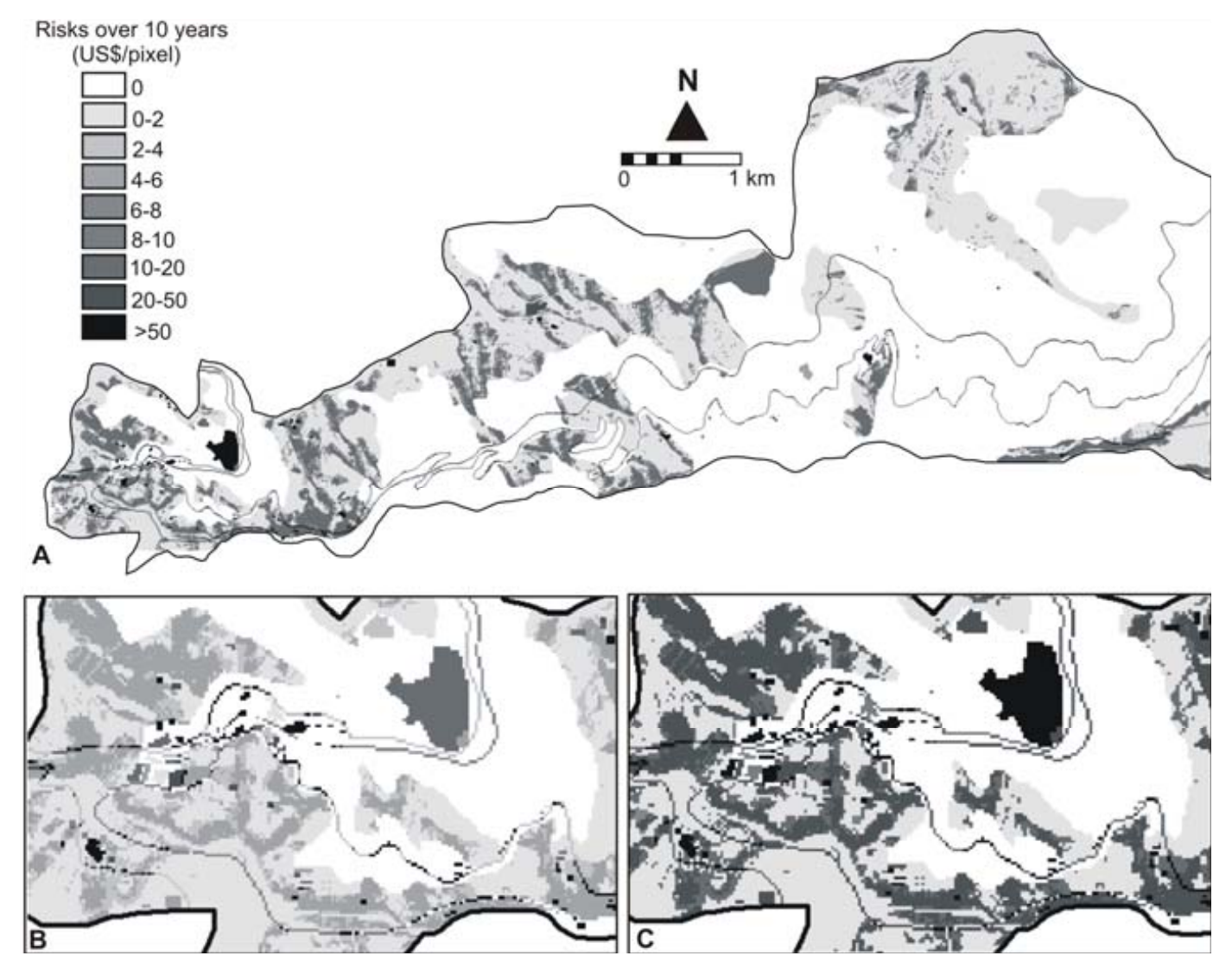

Fig. 11. Expected monetary losses due to landslide initiations in US\$ per pixel over a $10 \mathrm{yr}$ period. (A): shows distribution of the average loss in the study area. (B) and (C): show minimum and maximum loss, respectively, around Katteri.

we presented only those elements (buildings and infrastructures) that are located down slope of susceptible initiation areas, and we also have not included run-out losses of plantation areas. But for a number of individual buildings the runout losses are greater than the initiation losses. The average and maximum run-out losses are greater than the respective initiation losses for all buildings except those in Burliyar and Marapallam, which are located in high susceptible slopes. Run-out losses are much larger than initiation losses for the average and maximum landslide magnitudes because of their long run-out distance and higher probability of reaching the elements at risk. This difference is relatively small for the minimum landslide magnitude, except in Kallar area where the initiation loss is larger than the run-out loss.

In this study we focused only on direct landslide risks, however the area also has significant indirect risk mainly due to the traffic disruption caused by cut slope failures. In a previous study we estimated indirect losses, which from 5 to $50 \mathrm{yr}$ vary from US\$ 106560 to US\$ 240500 (Jaiswal et al., 2010a). The total loss (Table 6) would be higher if we include the indirect losses and also run-out losses of the plantations. The estimation of run-out risk to plantation areas requires information on the total deposition (inundation) area of poten- tial landslide debris, and since the proposed run-out model does not show areas likely to be inundated, the run-out loss to plantations remains unestimated.

The societal risk shown in Fig. 13 indicates that the risk of one or more lives lost is high in all settlements for which the run-out risk is analyzed. In comparison to the F-N curves from other countries as shown in Duzgun and Lacasse (2005), the estimated risk for 100 or more lives lost is lower than for China and Japan but higher than for Nepal and Italy. For 10 or more lives lost the value is lower than for Japan but higher than for Nepal, Columbia and Italy. It is important to note that this comparison may not be the truest representation, because in other countries researchers might have used different risk assessment approaches.

There are several inherent uncertainties in the methodology as well in the data used in this risk analysis, which we have tried to quantify by estimating ranges of expected losses. Uncertainties are related with the inherent assumption of the models, estimation of probabilities, and various assumptions made in order to simplify the risk analysis. These uncertainties may be of considerable significance and are inherent to risk estimation to landslides (Bell and Glade, 2004). It is important to indicate these uncertainties in order 


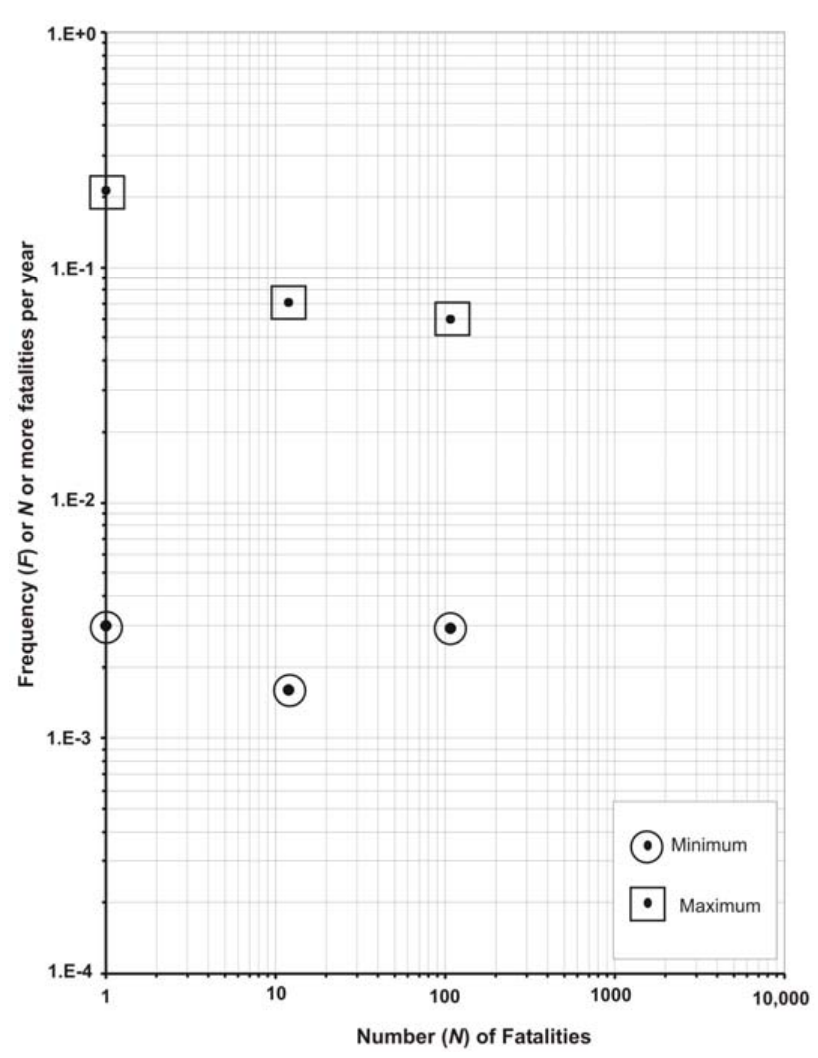

Fig. 12. Calculated F-N plots for people occupying the buildings in the study area.

to inform end users of what is known, what is unknown, and what is only partially understood (Stern and Fineberg, 1996).

Medium to very high uncertainty is associated with the hazard estimation due to the limitation of the model, its basic assumption, scale of the study, and availability of data. The use of return periods introduces a high uncertainty in the analysis, mainly due to the limited time period of the landslide inventory ( $23 \mathrm{yr}$ ). Therefore, the effect of landslide events with larger return periods cannot be properly evaluated. High uncertainty is associated with the probability of occurrence of landslides. The probability depends on the number and sizes of landslides expected in future. For example, the estimated probabilities for a single future landslide in the area will be much smaller than for 1000 future landslides (Chung and Fabbri, 2005). Thus, the estimated hazard is highly sensitive to the number and the sizes of future landslides. Since we derived the number of future landslides on natural slopes indirectly from a Gumbel analysis, which was originally performed on cut slopes, therefore the uncertainties associated with the Gumbel model such as the noncyclical nature of landslide events, extrapolation of the time period, etc. (Jaiswal et al., 2011) also hold true for this case. The assumption that for a given event $10 \%$ of landslides will occur on natural slope may not hold true always and every-

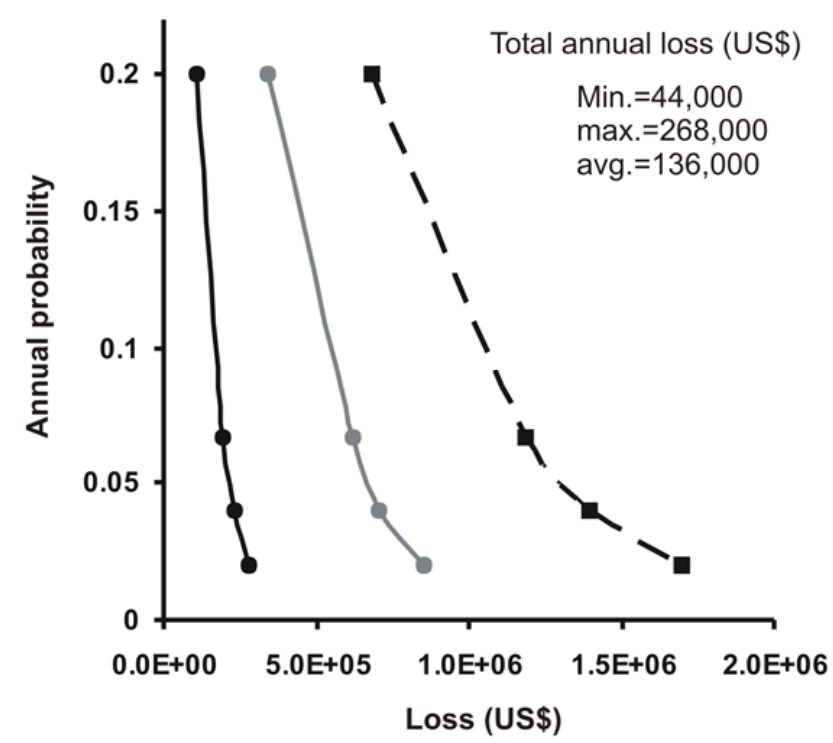

Fig. 13. Risk curves for total direct losses.

where. However, in this case the assumption is likely true because it was based on the two events which are representative of the study area. The 2006 event triggered most of the landslides east of Hillgrove, whilst the 2009 events affected areas west of Hillgrove.

Use of magnitude classes also introduces uncertainty in the hazard analysis. Since it is difficult to analyze risk for every landslide size, the choice of magnitude classes is optimal and the uncertainty is inevitable. However, we have included these uncertainties in risk analysis by defining a range of possible values. We quantified the uncertainty by considering the minimum, average, and maximum landslide sizes in each magnitude class and the corresponding minimum, average, and maximum run-out distances and vulnerability values. The uncertainty in the direct risk to properties is in the order of US\$ 224000 (difference between the total annual maximum and the total annual minimum loss). In fact, the uncertainties can be modeled using different scenarios based on ranges of values and using simulation methods such as a Monte Carlo simulation, which can be taken up in a further study.

A high uncertainty is also associated with the calculation of the population risk. This is mostly related to the estimation of the probability that a person will be killed given that the building is impacted by a landslide. Uncertainty in $P_{\mathrm{p} \text { :bt }}$ is less as it is easier to estimate based on occupancy type and number of people.

Methods for landslide risk assessment should always take these uncertainties into account and should be feasible to implement over larger areas without excessive requirements on data amounts. The uncertainties must be included in the analysis and the results should be expressed as a range of risk values, as demonstrated in this study where we estimated the 
range of expected losses for both initiation and run-out of landslides with different sizes. Considering the uncertainties associated with various input data used in the risk analysis, it is advisable that for planning of risk reduction strategies a detailed risk assessment in a large scale must be carried out.

As a final output the study provided risk curves (Figs. 9 and 10), total annual loss (Fig. 13), and F-N curves (Fig. 12), which could form the basis for a cost-benefit analysis and for designing risk reduction measures based on risk acceptance criteria, i.e., defining the limit of the acceptable and tolerable risk. Since India does not have a formally accepted risk acceptance criteria, we recommend to develop such criteria in future by starting with the data and criteria presented here.

Acknowledgements. We acknowledge the help of Southern Railway, Geo-technical Cell and Tea Estates of Coonoor, Tamilnadu, India for the relevant data and support. The research was carried out under the United Nations University- ITC School on Disaster Geo-Information Management (www.itc.nl/unu/dgim).

Edited by: A. Günther

Reviewed by: two anonymous referees

\section{References}

AGS, Australian Geomechanics Society and Sub-committee on Landslide Risk Management: Landslide risk management concepts and guidelines, Aust. Geomech., 35(1), 49-92, 2000.

Alexander, E. D.: Vulnerability to landslides, in: Landslide Hazard and Risk, edited by: Glade, T., Anderson, M. G., and Crozier, M. J., Wiley, London, 175-198, 2005.

Atkinson, P. M. and Massari, R.: A Generalized linear modeling of susceptibility to landsliding in the Central Apennines, Italy, Comput. \& Geosci., 24 (4), 373-385, 1998.

Baeza, C. and Corominas, J.: Assessment of shallow landslide susceptibility by means of multivariate statistical techniques, Earth Surf. Proc. Land., 26, 1251-1263, 2001.

Balachandran, V., Thanavelu, C., and Pitchaimuthu, R.: Marapallam landslide, The Nilgiri district, Tamilnadu, India: A case study, Proceedings of International Conference on Disasters and Mitigation, Madras, India, I: A4- 21-23, 1996.

Bell, R. and Glade, T.: Quantitative risk analysis for landslides Examples from Bldudalur, NW-Iceland, Nat. Hazards Earth Syst. Sci., 4, 117-131, doi:10.5194/nhess-4-117-2004, 2004.

Cannon, S. H. and Savage, W. Z.: A mass change model for debris flow, The Journal of Geology, 96, 221-227, 1988.

Carrara, A., Crosta, G. B., and Frattini, P.: Geomorphological and historical data in assessing landslide hazard, Earth Surf. Proc. Land., 28 (10), 1125-1142, 2003.

Cardinali, M., Reichenbach, P., Guzzetti, F., Ardizzone, F., Antonini, G., Galli, M., Cacciano, M., Castellani, M., and Salvati, P.: A geomorphological approach to the estimation of landslide hazards and risks in Umbria, Central Italy, Nat. Hazards Earth Syst. Sci., 2, 57-72, doi:10.5194/nhess-2-57-2002, 2002.

Catani, F., Casagli, N., Ermini, L., Righini, G., and Menduni, G.: Landslide hazard and risk mapping at catchment scale in the Arno River basin, Landslides, 2, 329-342, 2005.
Chung, C. J. and Fabbri, A. G.: Probabilistic prediction models for landslide hazard mapping, Photogramm. Eng. Rem. Sens., 65 (12), 1389-1399, 1999.

Chung, C. J. and Fabbri, A. G.: Systematic procedures of landslide hazard mapping for risk assessment using Spatial Prediction Models, in: Landslide Hazard and Risk, edited by: Glade, T., Anderson, M. G., and Crozier, M. J., Wiley, London, 139174, 2005.

Clerici, A., Perego, S., Tellini, C., and Vescovi, P.: A procedure for landslide susceptibility zonation by the conditional analysis method, Geomorphology, 48, 349-364, 2002.

Coburn, A. and Spence, R.: Earthquake Protection, John Wiley and Sons, Chichester, 1992.

Coe, J. A., Michael, J. A., Crovelli, R. A., and Savage, W. Z.: Preliminary map showing landslide densities, mean recurrence intervals, and exceedance probabilities as determined from historic records, Seattle, Washington, USGS Open-File report 00-0303, http://pubs.usgs.gov/of/2000/ofr-00-0303, cited on 15 July 2008, 2000.

Corominas, J. and Moya, J.: A review of assessing landslide frequency for hazard zoning purposes, Eng. Geol., 102, 193-213, 2008.

Crozier, M. J. and Glade, T.: Landslide hazard and risk: Issues, Concepts and Approach, in: Landslide Hazard and Risk, edited by: Glade, T., Anderson, M. G., and Crozier, M. J., Wiley, London, 1-40, 2005.

Dai, F. C., Lee, C. F, and Ngai, Y. Y.: Landslide risk assessment and management: an overview, Eng. Geol., 64, 65-87, 2002.

Duzgun, H. S. B. and Lacasse, S.: Vulnerability and acceptable risk in integrated risk assessment framework, in: Landslides Risk Management, edited by: Hungr, O., Fell, R., Couture, R., and Eberhardt, E., Taylor and Francis, London, 505-515, 2005.

Fell, R., Ho, K. K. S., Lacasse, S., and Leroi, E.: A framework for landslide risk assessment and management, in: Landslides Risk Management, edited by: Hungr, O., Fell, R., Couture, R., and Eberhardt, E., Taylor and Francis, London, 3-26, 2005.

Fell, R., Corominas, J., Bonnard, C., Cascini, L., Leroi, E., and Savage, W. Z.: Guidelines for landslide susceptibility, hazard and risk zoning for land use planning, Eng. Geol., 102, 85-98, 2008.

Finlay, P. J.: The risk assessment of slopes, School of Civil Engineering, University of New South Wales, Australia, PhD thesis, 1996.

Galli, M. and Guzzetti, F.: Landslide vulnerability criteria: A case study from Umbria, Central Italy, Environ Manage., 40, 649664, 2007.

Ganapathy, G. P., Mahendran, K., and Sekar, S. K.: Need and urgency of landslide risk planning for Nilgiri district, Tamilnadu state, India, International Journal of Geomatics and Geosciences, 1 (1), 29-40, 2010

Guzzetti, F., Carrara, A., Cardinali, M., and Reichenbach, P.: Landslide hazard evaluation: a review of current techniques and their application in a multi-scale study, Central Italy, Geomorphology, 31, 181-216, 1999.

Guzzetti, F.: Landslide fatalities and the evaluation of landslide risk in Italy, Eng. Geol., 58(2), 89-107, 2000.

Guzzetti, F., Reichenbach, P., Cardinali, M., Galli, M., and Ardizzone, F.: Probabilistic landslide hazard assessment at the basin scale, Geomorphology, 72, 272-299, 2005.

Hungr, O., Corominas, J., and Eherhardt, E.: Estimating landslide 
motion mechanism, travel distance and velocity, in: Landslide Risk Management, edited by: Hungr, O., Fell, R., Couture, R., and Eberhardt, E., Taylor and Francis, London, 99-128, 2005.

Jaiswal, P. and van Westen, C. J.: Estimating temporal probability for landslide initiation along transportation routes based on rainfall thresholds, Geomorphology, 112, 96-105, 2009.

Jaiswal, P., Westen, C. J. van., and Jetten, V.: Quantitative assessment of direct and indirect landslide risk along transportation lines in southern India, Nat. Hazards Earth Syst. Sci., 10, 12531267, doi:10.5194/nhess-10-1253-2010, 2010a.

Jaiswal, P., van Westen, C. J., and Jetten, V.: Quantitative landslide hazard assessment along a transportation corridor in southern India, Eng. Geol., 116, 236-250, 2010b.

Jaiswal, P., van Westen, C. J., and Jetten, V.: Quantitative assessment of landslide hazard along transportation lines using historical records, Landslides, doi:10.1007/s10346-011-0252-1, 2011.

Kong, W. K.: Risk assessment of slopes, Q. J. Eng. Geol. Hydroge, 35, 213-222, 2002.

Kuriakose, S. L., van Beek, L. P. H., and van Westen, C. J.: Parameterizing a physically based shallow landslide model in a data poor region, Earth Surf. Proc. Land., 34(6), 867-881, 2009.

Lee, E. M. and Jones, D. K. C.: Landslide Risk Assessment, Thomas Telford, London, 454 pp., 2004.

Michael-Leiba, M., Baynes, F., Scott, G., and Granger, K.: Quantitative landslide risk assessment of Cairns, Australia, in: Landslide Hazard and Risk, edited by: Glade, T., Anderson, M. G., and Crozier, M. J., Wiley, London, 621-642, 2005.

Nefeslioglu, H. A., Gokceoglu, C., and Sonmez, H.: An assessment on the use of logistic regression and artificial neural networks with different sampling strategies for the preparation of landslide susceptibility maps, Eng. Geol., 97, 171-191, 2008.
Neuhaeuser, B. and Terhorst, B.: Landslide susceptibility assessment using "weights-of-evidence" applied to a study area at the Jurassic escarpment (SW-Germany), Geomorphology, 86, 12 24, 2007.

Ohlmacher, G. C. and Davis, J. C.: Using multiple logistic regression and GIS technology to predict landslide hazard in northeast Kansas, USA, Eng. Geol., 69, 331-343, 2003.

Remaitre, A., Malet, J. P., Maquaire, O., Ancey, C., and Locat, J.: Flow behaviour and runout modelling of a complex debris flow in a clay-shale basin, Earth Surf. Proc. Land., 30, 479-488, 2005.

Remondo, J., Bonachea, J., and Cendrero, A.: Quantitative landslide risk assessment and mapping on the basis of recent occurrences, Geomorphology, 94, 496-507, 2008.

Stern, P. C. and Fineberg, H. V.: Understanding Risk: Informing Decisions in a Democratic society, National Academy Press, Washington DC, 1996.

Suzen, M. L. and Doyuran, V.: A comparison of the GIS based landslide susceptibility assessment methods: multivariate versus bivariate, Environ. Geol., 45, 665-679, 2004.

van Westen, C. J., Rengers, N., and Soeters, R.: Use of geomorphological information in indirect landslide susceptibility assessment, Nat. Hazards, 30(3), 399-419, 2003.

van Westen, C. J., Asch, T. W. J., and Soeters, R.: Landslide hazard and risk zonation-why is it still so difficult?, Bull. Eng. Geol. Environ., 65, 67-184, 2006.

Varnes, D. J.: Landslide Hazard Zonation: A Review of Principles and Practice, UNESCO, Daramtiere, Paris, 61, 1984.

Zezere, J. L., Oliveira, S. C., Garcia, R. A. C., and Reis, E.: Landslide risk analysis in the area North of Lisbon (Portugal): evaluation of direct and indirect costs resulting from a motorway disruption by slope movements, Landslides, 4, 123-136, 2007. 